\title{
Construction and evaluation of a mindfulness-based quality of life and well-being program (MQW) in a randomized trial
}

\author{
Patrick Jones $^{1} \mathbb{D} \cdot$ Peter Drummond $^{1}$
}

Accepted: 23 December 2021

(c) The Author(s) 2022

\begin{abstract}
Due to the multi-factorial nature of the self-report of happiness, an enhancement program was designed that focused on mental style (subjective processes), and relationships, work, money, health, and leisure (objective life domains). An examination of interventions revealed mindfulness training (subjective factors) and goal setting (objective factors) as effective change modalities. To address this, the Mindfulness-based Quality of Life and Well-being Program (MQW) was developed and evaluated against the Mindfulness Attention Awareness Scale, Quality of Life Index, Personal Wellbeing Index-Adult, Positive and Negative Affect Scale, the Satisfaction with Life scale, and the newly developed Clinical Quality of Life Scale (CLINQOL). To explore training protocol effects, the program was delivered in a graduated (6 weekly sessions x 2 hours) and intensive ( 2 consecutive days $\mathrm{x} 6$ hours) format. Using a randomized trial, participants were allocated across these conditions and a control. A total of 191 participants completed the study and were assessed at pre, post and follow up time points. Increases in mindfulness, quality of life, subjective well-being, and positive and negative affect (not life satisfaction), were greater in treated (combined formats) than control participants at post-test, and for mindfulness at follow up. Other than an increase in mindfulness for the 2 day condition at follow up, changes were similar in both intervention formats. Finally, to investigate what unique difference the MQW might have in comparison to teaching just mindfulness, the full version of the program was compared to an expanded section of the mindfulness component of the program. A total of 74 subjects began the program and filled out assessments across the three time periods. There was no difference between groups or an interaction between group and time. Overall, the findings provide preliminary evidence that a multi-dimensional training approach, using mindfulness and goal setting, may be a beneficial intervention model to enhance subjective and objective components in the perception of quality of life and well-being. However, further investigation into its added benefit to mindfulness alone is required.
\end{abstract}

Keywords Mindfulness $\cdot$ Quality of life $\cdot$ Subjective well-being $\cdot$ Interventions

\section{Introduction}

Quality of life (QoL) is a multi-factorial construct (Argyle, 1999; Hammer et al., 2019; Newman et al., 2013) seen as either health-related (Bakas et al., 2012), linked with the status/availability of resources (Hagerty \& Veenhoven, 2003; Sőrés \& Petô, 2015) or a more personal phenomenon mediated through the subjective perception of objective factors such as relationships, work, money, health or leisure

Patrick Jones

drpatrickjonesaustralia@gmail.com

1 College of Science, Health, Engineering and Education (SHEE), Murdoch University, 90 South Street, Murdoch, Western Australia 6150
(Brannan et al., 2012; Diener et al., 2017; Diener et al., 1999; Steptoe et al., 2015). It commonly refers to a person's perceptions, thoughts and feelings about such life conditions, and reactions to those conditions (Malkoç, 2011; The World Health Organisation, 2015).

QoL is typically distinguished from subjective well-being (SWB), sometimes colloquially known as 'happiness', which more refers to a global assessment of a person's life and typically includes both positive and negative affect and cognitive evaluations of life satisfaction (Diener et al., 2013; Luhmann et al., 2012; Lyubomirsky, 2013). However, these terms are often used interchangeably in research and public policy (Peasgood et al., 2019) even though they are usually underpinned by different theory and measurement fields (Dolan et al., 2016). 
For example, Tay, Kuykendall and Diener's (Diener et al., 2013) observation that "SWB can also be categorized by different life domains such as marriage, leisure, or job" (p.840) could easily have applied to quality of life. In response to this, Skevington and Böhnke (2018) make a strong case for a new Life Quality and Well-being model that integrates the overlapping and exclusive dimensions of both constructs. Whilst the identification of predictors and behaviours that might help individuals report higher quality of life and well-being is of primary research interest (Lachman et al., 2015; Nickel et al., 2019), there is comparatively less data about their enhancement (Sitbon et al., 2019) or, indeed, programs that specifically address quality of life and well-being (Corten et al., 1994; Cummins, 2003; Sergeant \& Mongrain, 2015).

In recent years, however, there has been growing research into the link between the field of mindfulness and well-being (Brewer et al., 2011; Hanley et al., 2014; Kreplin et al., 2018; Kudesia \& Nyima, 2014; Schoenberg \& Vago, 2018; Sedlmeier et al., 2012). Mindfulness training offers a range of concentration, awareness and loving kindness methods, though not always clearly distinguished (Van Dam et al., 2010), that focus on developing an individual's conscious awareness of thoughts, emotions (Kabat-Zinn, 2011) and the cultivation of compassion (Kirby et al., 2017).

By being assisted to observe these processes more objectively, individuals experience greater choice to engage in or disengage from these thoughts and emotions to optimise well-being (Feldman et al., 2010; Lindahl \& Britton, 2019; Segal et al., 2002). Through the development of skills such as objectivity and greater present moment awareness, outcomes of mindfulness training include reduced rumination, the activation of "task-positive" brain regions related to life skills such as conflict monitoring and cognitive control (Anderson et al., 2007; Vago \& Nakamura, 2011), and increased well-being (Compson, 2018; Malinowski, 2013; Tacon et al., 2004).

Similarly, in the fields of performance and goals theory (Brunstein, 1993; Sheldon et al., 2004) there has also been applicable research for the improvement of perceived quality of life (Threadgill \& Gable, 2018). For example, the attainment of personally relevant, intrinsic and meaningful goals (Emmons, 2003; Lapierre et al., 2007; Locke \& Schattke, 2018;) and the process of achieving or moving toward goals has been associated with positive affect and well-being (Plemmons \& Weiss, 2013) across the life span (López Ulloa et al., 2013). For example, people who follow intrinsically derived goals are more able to integrate the diverse areas of their lives, and their perception of goal success through reducing the gap between their expectations and outcomes (achievement-aspiration gap), increases the perception of quality of life (Land et al., 2011).
The goal of this research was to design a program that targeted both the subjective components of well-being and the objective components of quality of life. As empirical reviews of mindfulness training have found mindfulness to be effective in improving mental processes (Ortner \& Zelazo, 2014; Thomas et al., 2016) relevant to perceived well-being and quality of life (Keng et al., 2011), mindfulness appeared to be a suitable inclusion in a program that taught the cognitive skill sets foundational to the development and maintenance of subjective well-being.

There were some distinct advantages that came with the choice of mindfulness, one specifically relevant to the formulation of perceived quality of life, that mindfulness may be able to reduce the "achievement-aspiration gap" by assisting someone to "want what one has," which in turn leads to an increase in the perception of quality of life (Brown et al., 2009). Furthermore, there was some early precedent with Smith, Compton and West's (1995) finding that the addition of meditation to Fordyce's $(1983,1988)$ earlier happiness and quality of life program improved its efficacy. Finally, the strong presence of mindfulness in the intervention literature, and the well documented findings of its impact upon relevant areas such as positive self-esteem (Robins et al., 2001), internal locus of control (Strickland, 2016), the ability to modulate behaviour (Raffone \& Srinivasan, 2009), and interpersonal skills (Shonin et al., 2015) seemed sufficient reason for choosing mindfulness as a key focus of the intervention.

Similarly, as the research indicated that goal setting is an effective method to heighten achievement in the major life domains (Grouzet et al., 2005; Seijts et al., 2013), this methodology was included in the intervention to address the objective components of quality of life. In constructing the intervention, this research aimed to address a gap in the quality of life and subjective well-being literature, as much of current research focuses on predictors and assessment than on intervention design. By combining mindfulness to address the subjective components of well-being, and goal setting for improvement of the objective components of perceived quality of life, this research sought to provide a novel and more comprehensive approach to enhancing the self-report of happiness.

Furthermore, a perceived gap in the mindfulness intervention literature was also addressed. It was considered that there may be a greater focus on the effect of mindfulness upon subjective processes or health-related outcomes, rather than creating change in objective life domains identified in the quality of life and subjective well-being literature. By integrating findings from the QoL field there was an opportunity to examine the efficacy of mindfulness to impact identified quality of life domains.

The five life domains chosen to work on that were identified as having an impact on the perception of quality of life were: relationships, work, money, health and leisure. 
In brief, the multi-axial domain of relationships satisfaction is one of the major predictors of reported well-being (Carr et al., 2014; Demir \& Weitekamp, 2007; Proulx et al., 2007) and can include intimate relationships, family, friends and colleagues. It is founded on the perception of connection, bonding and satisfying interaction with others (Gere \& Schimmack, 2011) and can act as a buffer for stress and social support (Brannan et al., 2012), help achieve positive health outcomes (Taylor, 2010), and increased well-being (Tan \& Tay, 2017).

Work also plays a significant role in quality of life (Van Katwyk et al., 2000) and includes work conditions (Cranny et al., 1992), supportive management (Monnot \& Beehr, 2014), satisfaction of psychological needs at work (Parfyonova et al., 2019), and vocational satisfaction being linked to greater life satisfaction (Shimazu et al., 2015). Money appears to play a small but critical role in the perception of quality of life (Diener \& Biswas-Diener, 2009) with financial goal setting having positive outcomes on health and wellbeing (Brackertz, 2013) and life satisfaction associated with gross domestic product (Hagerty \& Veenhoven, 2003). However, a negative effect can also be experienced if material goals are prized more than other values (Diener $\&$ Biswas-Diener, 2009), and financial problems have also been found to be a predictor of depression (Huppert \& So, 2011).

Health-related quality of life research is a burgeoning area (Brazier \& Tsuchiya, 2015; Cummins et al., 2004; SalvadorCarulla et al., 2014) and involves a reciprocal relationship between health status and well-being, with affect correlating with symptom checklists (Krampen, 1999), physical functioning, pain and general health (Czekierda et al., 2019; Karimi \& Brazier, 2016). The relationship also appears to be bidirectional, with people that present with heart disease, arthritis, and lung disease having increased levels of depressed mood and impaired hedonic and eudemonic wellbeing (Boehm \& Kubzansky, 2012; Steptoe et al., 2015).

Finally, leisure has a small but significant association with mental health (Lloyd \& Auld, 2002; Tinsley \& Eldredge, 1995), and life satisfaction (Rodríguez et al., 2007). Again, a multidimensional construct, it can also act as a buffer for stress through the pursuit of rewarding activities (Csíkszentmihályi, 2014) that transcend daily concerns (Sonnentag $\&$ Niessen, 2008). Through the effort-recovery process (Tay et al., 2014) it is seen that resilience is built, which plays a protective role in the maintenance of well-being (Denovan \& Macaskill, 2016).

The trial design chosen was a three-arm randomised controlled trial (RCT) comparing two experimental treatments [graduated learning six week format (6 weeks x 2 hours), a two day intensive format (2 days x 6 hours) and control], adhering to the Consolidated Standards of Reporting Trials (CONSORT) (Schulz, 2010). The rationale for choosing a multi-arm randomized clinical trial that evaluated more than one new intervention concurrently included: the increased probability of finding an effective intervention; the increase of efficiency (lower costs due to better use of resources); sharing of a control reduces total required sample size compared to separate two-arm trials; and offering participants more possibilities of being allocated to another intervention option could result in a greater number of people enrolling (Juszczak et al., 2019).

In study 1 , the first aim was to test the hypothesis that the combined intervention itself ( six week and two day version) was more effective at improving self-report of quality of life and subjective well-being in comparison to a waitlist control group at post-test and follow up. The second aim, in response to research into teaching frameworks that create "learning that lasts" (Lee, 2001), explored which training formats are most effective for complex learning (Van Merriënboer \& Kirschner, 2017). As there is some indication that there is little or no difference in achievement between compressed and traditional formats (Arrey, 2005; Wlodkowski \& Westover, 1999), the second aim of this study was to provide further data (Halldorsdottir \& Ollendick, 2016) on whether the intervention design (either six week or two day version) influenced gains in well-being. This was regarded as providing useful information on the efficacy of each intervention delivery option.

In study 2, the aim was to test the hypothesis that the full Mindfulness-based Quality of Life and Well-Being Program (MQW) would be more effective at improving self-report of quality of life and subjective well-being than teaching mindfulness alone. To test this, the follow up study was conducted comparing the full 6-week version of the MQW program to the mindfulness section of the program. This was designed by delivering the mindfulness content of the first 2-weeks of the full program across 6 weeks and increasing the practise time of the exercises.

\section{Study 1}

\section{Method}

\section{Program Development}

Interventions which give participants both information and the skills to positively change their behaviours (Fishbach \& Hofmann, 2015; Sin \& Lyubomirsky, 2009) result in increased quality of life (Bonow et al., 2012; Folette et al., 2001). As such, the Mindfulness-based Quality of Life and Well-Being Program (MQW) was made up of both psychoeducation and interactive exercises, and participants were invited to apply the program to their life circumstances so as to consolidate treatment gains (Brown et al., 2017). 
The program delivery sequence of first teaching theory (both mindfulness and quality of life/well-being) before teaching method drew from quality of life theory and from previous mindfulness programs (Kabat-Zinn, 1990; Shapiro et al., 2007) that introduced participants to general mindfulness theory and principles, before teaching techniques and exercises. It also mapped the order of traditional Buddhist mindfulness training structures made up of study, contemplation and meditation (Kudesia \& Nyima, 2014).

This latter sequenced approach to mindfulness begins with theory (study) before moving to its application in daily life (contemplation). Methods (meditation) to build attentional regulation skills and assist the decrease of discursive cognition are added, before moving to deconstruction methods that dissolve the sense of self and separateness (Lindahl $\&$ Britton, 2019). To address the objective life conditions, the goal setting structure mapped Freund and Baltes' (2002) elective selection. Here, participants chose a particular goal or set of goals to pursue as a means to improve their perception of quality of life (Teshale \& Lachman, 2016).

\section{Program Content}

The program was divided into three sections. The first section included an introduction into the general findings of the quality of life and subjective well-being research. Participants were then introduced to the application of mindfulness in daily life and its relevance to well-being enhancement. Finally, they were introduced to ten different mindfulness attributes identified in the literature, before being trained in methods that would enhance these qualities. Mindfulness training methods broadly fell under categories similar to those defined by Lutz et al. (2008): attentional [focused attention (observation of the breath) and open monitoring (body scan)], constructive (loving kindness and compassion); and deconstructive (inquiry into thoughts and emotions). Participants were trained in class and were also given class exercises and set homework to practise (see Appendix A).

The ten attributes summarising some of the key qualities in mindfulness that were examined are: Present Moment Awareness (A present time, moment by moment awareness of all sensation); Neutrality (To neutrally observe thoughts, emotions or physical sensation as passing events); Clarity (The ability to identify clearly one's beliefs and emotions); Regulation of Attention (The ability to both disengage from thought and direct attention where required); Thought Suspension (The ability to suspend engagement in thought and just be); Openness (The ability to have emotional openness to all experiences); Acceptance (An ability to accept/ allow rather than avoid either good or bad feelings); Relaxation (A natural relaxation response to events); Response Freshness (To respond uniquely/freshly to each new event non-habitually); Equanimity (The capacity to treat others non-judgmentally/compassionately).

In Section two, participants were trained to apply the principles and methods of mindfulness to the five major life areas previously identified in the literature: relationships, work, money, health and leisure. For example, through education and exercises they explored how to apply the mindfulness attributes of non-judgmental awareness, interpersonal equanimity, or emotional openness to relationship conflict. Participants were then trained in goal setting theory and its relationship to quality of life and well-being. Participants rated their perception of quality of life with an expectationoutcome gap calculation, before being trained in setting SMART (specific, measurable, achievable, realistic and time-framed) goals and short term strategies across each of the five quality of life areas. In this section, participants were also set homework to follow through with their identified strategies and goals.

In section three, participants were trained in how to apply mindfulness to cultivate a robust mental state of well-being. As well-being typically is associated with areas such as selfconcept (Hutz et al., 2014) and internal locus of control (Larson, 1989; Locke \& Schattke, 2018; Strickland, 2016), participants received psycho-education to build a more robust sense of a "neutral, non-judgmental" self that was less prone to reacting to life events. They were also invited to the extension of this, as offered in traditional mindfulness (Kudesia \& Nyima, 2014), which included the cultivation of the non-dual sense of self as "just witnessing", pure awareness (Jones, 2019; Vago \& Silbersweig, 2012). This state, in requiring less focus for self-regulation, has been found to increase attentional availability to phenomena (Raffone \& Srinivasan, 2009), and is relevant to a more resourceful response to life conditions.

To complement psychoeducation, the third category of deconstructive methods (Lutz et al., 2008) was explored with participants practising self-inquiry (examination of the relationship between the self as observer and the objects it observes) and perspective taking methods, along with take-home exercises to consolidate gains and build stronger behavioural repertoires. For the 6-week group, each of the three sections was split into two sessions of 2 hours each (aggregating 12 hours of total content across the three sections plus homework) and for the 2-day group the three sections each constituted four hours of content plus homework.

\section{Participants}

As the identification of optimal recruitment methods require that recruitment and retention strategies need to be relevant to the target population and the research methodology used (Newington \& Metcalfe, 2014), the rationale for the strategies selected included targeting a relevant 
demographic (psychologically healthy, English speaking adults), and reducing participant burden through easy access to portals and online surveys. The first recruitment strategy involved an online university student portal that provided information to students seeking to participate in research projects. Volunteers logged in and read general information about the program and an outline of time commitments. Because the portal was password protected, details of volunteers remained confidential.

The second recruitment method chosen was chain referral or snowball sampling. This sampling technique was selected as it is simple, cost-efficient, needs less planning and resources. These benefits were seen to outweigh any disadvantages such as less control over the sampling method and its representativeness. Questionnaires were handed out to people within several organisations, with each group providing a secure place for completed questionnaires to be returned in sealed envelopes.

Inclusion criteria for participation comprised a requirement that participants be a minimum of eighteen years old, and that they read the introductory brochure, university ethics pro forma letter, and complete the consent form, with the option to receive anonymised general results. As mindfulness meditation may be contraindicated under certain circumstances (Dobkin et al., 2011), exclusion criteria for participation included anyone whose primary language was other than English, or reported dependency on medical or psychiatric care, or anyone deemed to be "at risk" as determined by survey information and follow up interview. During the intervention, assessment of risk of harm with a possible consequence of exclusion included visible criteria (visible signs of self-harm or harm from others), or behavioural criteria such as disturbed affect (e.g. crying, anger).

Based on previous research (Sarenmalm et al., 2013), to detect differences between the three groups (6-week, 2 -day, and control), 50 participants per group (150 participants in total) were needed to have adequate power $(0.80)$ to detect medium effect sizes $(\mathrm{d}=0.50)$. Due to possible attrition rates of approximately 50\% (Dreher, 2009) a minimum of 300 participants in total were required.

To ensure that each participant had an equal chance of being allocated to any of the conditions, to eliminate any selection bias, and to test the efficacy of treatment (Suresh, 2011), a randomisation procedure was employed. A random number generator was used to assign participants to one of the two interventions or to the waitlist control condition. A list of random numbers between one and three was generated for each participant, based on the following specifications. Initially a maximum number of choices was entered (e.g. 350) followed by a minimum (1) and maximum value (3). A calculate button was then clicked to create a table of random numbers.
The primary researcher (who did not deliver the program to manage potential bias) was responsible for generating the random allocation sequence, the enrolment of participants, and assignation to condition. The randomisation sequence was concealed until interventions were assigned and participants were then informed of their allocated condition. As all three conditions were distinct (6-weekly, 2-day and waitlist control) it was not possible to blind participants or clinicians. In acknowledgement of this limitation, the treatment of the groups was standardised as much as possible (the course content for the 6-weekly and 2-day groups was the same), and objective, reliable assessment measures were used to reduce subjective bias and the need to blind data collectors or analysts (Karanicolas et al., 2010).

An initial sample of 342 subjects was randomly allocated into the three conditions (Weekly $=117$, Two day $=105$ and Control $=120$ ). The age range was $18-80$ years and a median age of 44 years with $79 \%$ females and $21 \%$ males. Because the initial online survey aimed to cast a wide net to recruit a large sample, a high attrition was expected. Hence, pre (baseline) scores from survey respondents who did not participate further were trimmed. Adjusting for attrition, 191 subjects (Weekly $=53$, Two day $=49$ and Control $=89$ ) completed the program and filled out assessments across the three time periods. Complete data was collected from 167 participants and incomplete data was collected from the additional 24 participants (Weekly $=4$, Two day $=8$ and Control =12).

Another 22 people started the program but either did not complete at least 4 sessions of the six weekly condition or only completed one day of the two day intervention. The completion criterion for the six week group was defined as 4-6 sessions, as participants who attended 1-3 sessions demonstrated a clear drop off trajectory toward the end of the program whilst most participants who missed 1 or 2 sessions still completed the final session. The completion criterion for the two day group was attendance of both days as 1 day attendance (equivalent to the first three sessions in the six week group) was not seen as sufficient content exposure.

\section{Assessment}

Five standardised instruments were chosen to assess the intervention (see Appendix B). Data was collected across the three time periods (pre, post and follow up) and analyses were done on summed change scores (Estrada et al., 2019) (pre-test score minus post-test score and post-test score minus follow up-test score). The Mindfulness Attention Awareness Scale (MAAS) (Brown \& Ryan, 2003) was chosen to assess mindfulness. The MAAS is a 15-item, selfreport measure (e.g., "I find myself doing things without paying attention") rated on a scale ranging from 1 to 6 which is totalled giving a range from 15-90. The scale correlates 
with other psychometric measures of mindfulness (Baer et al., 2006), and internal consistency reliability is high $($ Cronbach's alpha $=.82)$ (Brown \& Ryan, 2003).

Quality of Life was measured with the Quality of Life Index (AQoL-(8-D) (Maxwell et al., 2016). The AQoL is a multi-attribute utility instrument to assess the psychosocial aspects of quality of life. Correlations between the AQoL and five other standardised multi-attribute utility instruments range from .49 to .65 and its Cronbach alpha coefficient is 0.96 (Richardson et al., 2013).

Subjective well-being was measured with the Personal Wellbeing Index-Adult (PWI-A) (International Wellbeing Group, 2006, 2013). In support of convergent validity, the PWI-A correlates .78 with Diener, Emmons, Larsen and Griffin's (Diener et al., 1985) Satisfaction with life scale (Thomas, 2005). Cronbach's alpha falls between .70 and .85 with a test-retest reliability correlation coefficient of 0.84 over an interval of 1-2 weeks (International Wellbeing Group, 2013; Lau et al., 2005).

As research has indicated a two-factor structure of general positive affect (PA) and negative affect (NA) (Lac \& Donaldson, 2018), and they represent the emotional components of SWB (Diener et al., 1985), the Positive and Negative Affect Schedule (PANAS) was included in the test battery (Watson et al., 1988). In the PANAS, respondents are asked to rate ten adjectives that depict positive and ten negative emotions using a five-point scale from "very slightly or not at all" to "extremely". The 20-item self-report instrument has good internal consistency with a Cronbach's alpha of .88 for PA, and .87 for NA and is robust across a wide range of populations (Dahiya \& Rangnekar, 2019; Humboldt et al., 2017).

Similarly, as research has also identified both affective and cognitive components to subjective wellbeing, the Satisfaction with Life scale (SWL) (Diener et al., 1985) was chosen to assess change in participants' satisfaction with their life as a whole. Whilst the scale does not assess satisfaction with life domains per se (e.g. health) it has been shown to identify changes in a single factor of life satisfaction (Whisman \& Judd, 2016) including in response to clinical interventions (Pavot \& Diener, 1993, 2009). The scale has five questions rated from (1) "Strongly disagree" to (7) "Strongly agree". Diener et al. (1985) have reported a Cronbach's alpha of .87 and test-retest reliability of .82 at two month retest.

A newly constructed measure, the Clinical Quality of Life Scale (CLINQOL), that matched the content of the MQW program was also chosen as it evaluated the subjective domains and objective domains of perceived well-being and quality of life in a single scale (see Appendix C). Made up of seven factors (Mental Style, Life Management, Relationships, Work, Money, Health, Leisure), items within each category formed internally consistent scales with Cronbach's Alpha ranging from .504 to .904 . The overall reliability of the scale was .907 which falls within the acceptable minimum of .70 for a newly developed scale (Lance et al., 2006; Nunnally \& Bernstein, 1994). The CLINQOL was administered pre-post to participants of the two day program.

\section{Procedure}

The psycho-education and skills training content was delivered by a clinical psychologist registrar with previous experience in delivering the mindfulness-based cognitive therapy program (Segal et al., 2002). Treatment fidelity was maximized by supervised rehearsal of training content and post-delivery assessment. The three conditions were run within a 12 week period (the 6 -week program ran from weeks 2-8 and the 2-day intensive program in week 8 ) with the online survey being simultaneously completed for the treatment and waitlist control conditions at the same pre, post and follow up time points (Pre $=0$ weeks, Post $=8$ weeks and Follow up $=12$ weeks). Data was collected online or on location, at either the beginning or end of treatment as per time points.

\section{Results}

Prior to conducting the analyses, outliers and normality of the variables were examined, with the outlier labelling rule (Hoaglin et al., 1986) detecting no significant outliers. Most variables were normally distributed, except subjective well-being and negative affect. Logarithmic transformation of negative affect and square root transformation of subjective well-being adjusted the variables to within the normal range. To assess baseline differences in randomisation, a chi square test of independence/relatedness was conducted to investigate the relationship between discrete variables and the three conditions. This analysis was done post intervention, in accordance with the CONSORT statement that choosing covariates based on significance tests for baseline differences might lead to omissions of important covariates (Moher et al., 2010; De Boer et al., 2015). There was no significant difference between groups.

To assess if there may be some overlap in what is being measured across some variables, a correlation analysis of change scores (pre-test score minus post-test score), was initially conducted to investigate relationships among measures of mindfulness, quality of life, subjective well-being, positive affect, negative affect and life satisfaction. As there were significant relationships among dependent variables, MANOVA was conducted across three time points (pre, post and follow up) of scores at each time point to examine the effect of treatment upon the six dependent variables.

For univariate effects, planned contrasts (pre-post and post-follow up) were run to clarify interactions and, if significant, t-tests were conducted within each condition at 
Table 1 Intention to Treat mean scores at pre, post, and follow up for treatment $(\mathrm{n}=102)$ and control $(n=89)$

\begin{tabular}{|c|c|c|c|c|c|c|}
\hline \multirow[t]{2}{*}{ Measure } & \multicolumn{2}{|l|}{ Pre } & \multicolumn{2}{|l|}{ Post } & \multicolumn{2}{|c|}{ Follow-up } \\
\hline & M & $(S D)$ & M & $(S D)$ & M & $(S D)$ \\
\hline \multicolumn{7}{|l|}{ MAAS } \\
\hline Treatment & 48.73 & (12.81) & 55.87 & (11.60) & 60.00 & (11.23) \\
\hline Control & 50.33 & (12.61) & 53.26 & (14.05) & 54.74 & (14.37) \\
\hline \multicolumn{7}{|l|}{ AQoL } \\
\hline Treatment & 78.45 & (16.02) & 68.99 & (14.77) & 66.02 & (13.59) \\
\hline Control & 82.01 & (16.16) & 77.92 & (16.47) & 76.84 & (17.07) \\
\hline \multicolumn{7}{|l|}{ PWI } \\
\hline Treatment & 52.68 & (13.47) & 59.41 & (12.07) & 60.36 & (11.83) \\
\hline Control & 49.21 & $(12.42)$ & 51.43 & (13.63) & 51.97 & (13.75) \\
\hline \multicolumn{7}{|l|}{ PA } \\
\hline Treatment & 29.44 & (7.88) & 34.04 & $(6.94)$ & 34.75 & $(7.17)$ \\
\hline Control & 29.36 & $(7.32)$ & 31.43 & $(7.82)$ & 31.81 & $(8.20)$ \\
\hline \multicolumn{7}{|l|}{ NA } \\
\hline Treatment & 21.32 & $(7.25)$ & 17.69 & $(5.48)$ & 16.89 & $(6.52)$ \\
\hline Control & 22.25 & (7.67) & 20.96 & $(8.42)$ & 20.16 & $(7.33)$ \\
\hline \multicolumn{7}{|l|}{ SWLS } \\
\hline Treatment & 20.93 & $(7.31)$ & 22.94 & $(6.81)$ & 24.24 & $(6.55)$ \\
\hline Control & 19.48 & $(6.75)$ & 21.08 & (7.37) & 21.61 & (7.58) \\
\hline
\end{tabular}

For mindfulness (MAAS), quality of life (reverse scored) (AQoL), subjective well-being (PWI), positive and negative affect (PANAS) and life satisfaction (SWLS). pre, post and follow up and between conditions at each time point. Intention to treat (last score carried forward for missing values) analyses are presented for completers (analyses limited to participants with complete data provided no new information). Descriptive statistics, correlations between dependent variables, results from multivariate and univariate analyses, and t-tests are summarised in Tables 1, 2, 3, 4, 5 and 6 .

\section{Treatment Versus Waitlist Control Intention to Treat Data}

In the correlational analysis (Table 1) there were moderate correlations among most dependent variables $\left(p^{* *}<.01\right)$ at pre-post, with the only exception being the relationship between mindfulness and life satisfaction indicating that, on the whole, the variables measured related elements. At post-follow up there were again correlations among most
Table 2 Intention to treat prepost and post-follow up change scores correlational matrix for treatment and control $(\mathrm{n}=191)$

\begin{tabular}{|c|c|c|c|c|c|c|}
\hline & MAAS & AQoL & PWI & PA & NA & SWLS \\
\hline \multicolumn{7}{|l|}{ Pre-post } \\
\hline MAAS & 1 & & & & & \\
\hline AQoL & $-.442 * *$ & 1 & & & & \\
\hline PWI & $-.300 * *$ & $.599 * *$ & 1 & & & \\
\hline PA & $.177 * *$ & $-.538 * *$ & $-.423 * *$ & 1 & & \\
\hline NA & $-.212 * *$ & $.557 * *$ & $.364 * *$ & $-.439 * *$ & 1 & \\
\hline SWLS & .132 & $-.532 * *$ & $-.476 * *$ & $.371 * *$ & $-.296 * *$ & 1 \\
\hline \multicolumn{7}{|c|}{ Post-Follow up } \\
\hline MAAS & 1 & & & & & \\
\hline AQoL & $-.468 * *$ & 1 & & & & \\
\hline PWI & $-.364 * *$ & $.591 * *$ & 1 & & & \\
\hline $\mathrm{PA}$ & $.280 *$ & $-.598 * *$ & $-.514 * *$ & 1 & & \\
\hline NA & -.131 & $.602 * *$ & $.314 * *$ & $-.445 * *$ & 1 & \\
\hline SWLS & $.208 * *$ & $-.627 * *$ & $-.542 * *$ & $.510 * *$ & $-.455^{* *}$ & 1 \\
\hline
\end{tabular}

For mindfulness (MAAS), quality of life (AQoL), subjective well-being (PWI), positive and negative affect (PANAS) and life satisfaction (SWLS) $(* * p<0.01)$. 
Table 3 Intention to Treat pre-post-follow up MANOVA outcomes (Wilk's Lambda) for treatment $(n=102)$ and control $(\mathrm{n}=89)$

\begin{tabular}{|c|c|c|c|c|c|}
\hline Category & Wilk's lambda & $\mathrm{F}$ & $\mathrm{df}$ & Sig & Partial Eta ${ }^{2}$ \\
\hline \multicolumn{6}{|l|}{ pre-post-follow up } \\
\hline Group & .893 & 3.689 & 184.000 & $.002 *$ & .107 \\
\hline Time & .259 & 42.374 & 178.000 & $.000 * * *$ & .741 \\
\hline Group x Time & .853 & 2.547 & 178.000 & $.004 *$ & .147 \\
\hline \multicolumn{6}{|l|}{ pre-post } \\
\hline Group & .915 & 2.851 & 184.000 & .011 & .085 \\
\hline Time & .356 & 55.363 & 184.000 & $.000 * * *$ & .644 \\
\hline Group x Time & .913 & 2.938 & 184.000 & $.009 *$ & .087 \\
\hline \multicolumn{6}{|l|}{ post-follow up } \\
\hline Group & .860 & 4.982 & 184.000 & $.000 * * *$ & .140 \\
\hline Time & .852 & 5.336 & 184.000 & $.000 * * *$ & .148 \\
\hline Group x Time & .962 & 1.216 & 184.000 & .300 & .038 \\
\hline
\end{tabular}

For mindfulness (MAAS), quality of life (AQoL), subjective well-being (PWI), positive and negative affect (PANAS) and life satisfaction (SWLS) $\left({ }^{*} p<0.05,{ }^{*} p<0.01,{ }^{* *} p<0.001\right.$; pre-pst-fw $=$ pre score-post score-follow up score) dependent variables other than mindfulness and negative affect (Fig. 1).

As indicated in Table 2, at both pre-post and post-follow up, scores across all measures improved. This was reflected in the multivariate analyses with an effect between groups across time at pre-post but was not borne out at post-follow up (Table 3 and Table 4). Whilst only pre-post reached significance, post-follow up gains did not return to baseline but were maintained with marginal improvement. The weak to moderate significant interactions between groups across time (pre-post) for mindfulness, quality of life and subjective well-being, also suggests that each component of the threepart program was effective (Table 5).

\section{Six Week Versus Two Day Intention to Treat Data}

Multivariate analyses revealed an effect across time but no difference between groups and no interaction between group and time (Table 6). At follow up, however, the 2-day participants demonstrated a significant increase in selfreported mindfulness in comparison to their 6-week group counterparts, bringing them closer in line. This may suggest that mindfulness is more receptive to a graduated learning approach than other measured variables, and once participants had time to practise after their two day training, they were able to make similar gains to those of the 6-week group (Fig. 2).

\section{Two-Day Clinical Quality of Life Scale (CLINQOL) Data}

A newly developed measure, the Clinical Quality of Life Scale (CLINQOL), that specifically matched the targeted quality of life domains of the MQW program, was used to evaluate the pre-post intervention changes in perceived quality of life. In view of the length of the multidimensional survey, the CLINQOL was administered only to participants pre and post of the two day condition with significant effects being reported (see Table 7).
Table 4 Intention to Treat pre-post-follow up F ratios for treatment $(\mathrm{n}=102)$ and control $(n=89)$

\begin{tabular}{|c|c|c|c|c|c|c|c|}
\hline \multirow[b]{2}{*}{ Measure } & \multirow[t]{2}{*}{ GROUP } & \multicolumn{3}{|l|}{ TIME } & \multicolumn{3}{|c|}{ GROUP x TIME } \\
\hline & & pre-pst-fw & pre-pst & pst-fw & pre-pst-fw & pre-pst & pst-fw \\
\hline Multivariate & $3.69 * *$ & $42.37 * * *$ & $55.36 * * *$ & $5.36^{* * *}$ & $2.55^{* *}$ & $2.94 * *$ & 1.21 \\
\hline MAAS & 1.57 & $65.58 * * *$ & $50.11 * * *$ & $24.53 * * *$ & $12.41 * * *$ & $8.76^{* *}$ & $5.45^{*}$ \\
\hline AQoL & $14.16^{* * *}$ & $63.23 * * *$ & $74.02 * * *$ & $7.83 * *$ & $10.56^{* * *}$ & $11.63 * *$ & 1.71 \\
\hline PWI & $16.26 * * *$ & $25.24 * * *$ & $43.04 * * *$ & 1.16 & $4.37 *$ & $5.82 *$ & .101 \\
\hline PA & $4.06^{*}$ & $35.75 * * *$ & $44.32 * * *$ & 1.69 & $4.97 * *$ & $6.40 *$ & .157 \\
\hline NA & $7.82 * *$ & $25.33 * * *$ & $23.50 * * *$ & $4.12 *$ & $4.43 *$ & $4.04 *$ & .762 \\
\hline SWLS & $4.52 *$ & $27.80 * * *$ & $24.14 * * *$ & $7.09 * *$ & 1.31 & .32 & 1.25 \\
\hline
\end{tabular}

For mindfulness (MAAS), quality of life (AQoL), subjective well-being (PWI), positive and negative affect (PANAS) and life satisfaction (SWLS) $\left({ }^{*} p<0.05,{ }^{*} p<0.01,{ }^{* *} p<0.001\right.$; pre-pst-fw $=$ pre score-post score-follow up score) 
Table 5 Intention to Treat mean scores at pre, post, and follow up for six week $(n=53)$ and two day $(n=49)$ participants

\begin{tabular}{|c|c|c|c|c|c|c|}
\hline \multirow[t]{2}{*}{ Measure } & \multicolumn{2}{|l|}{ Pre } & \multicolumn{2}{|l|}{ Post } & \multicolumn{2}{|c|}{ Follow up } \\
\hline & M & $(S D)$ & M & $(S D)$ & M & $(S D)$ \\
\hline \multicolumn{7}{|l|}{ MAAS } \\
\hline 6-week & 50.53 & $(13.25)$ & 58.79 & (10.61) & 61.06 & (11.01) \\
\hline 2-day & 46.78 & (12.14 & 52.71 & (11.89) & 58.86 & (11.36) \\
\hline \multicolumn{7}{|l|}{ AQoL } \\
\hline 6-week & 76.47 & $(15.40)$ & 65.77 & (12.84) & 64.51 & (12.11) \\
\hline 2-day & 80.59 & (16.55) & 72.47 & (16.01) & 67.65 & (14.98) \\
\hline \multicolumn{7}{|l|}{ PWI } \\
\hline 6-week & 52.94 & $(13.75)$ & 60.77 & (11.63) & 61.32 & (11.25) \\
\hline 2-day & 52.39 & (13.29) & 57.94 & $(12.47)$ & 59.33 & (12.46) \\
\hline \multicolumn{7}{|l|}{ PA } \\
\hline 6-week & 30.06 & $(7.67)$ & 35.11 & $(6.28)$ & 35.68 & $(6.34)$ \\
\hline 2-day & 28.78 & $(8.12)$ & 32.88 & $(7.48)$ & 33.76 & $(7.91)$ \\
\hline \multicolumn{7}{|l|}{ NA } \\
\hline 6-week & 20.04 & $(6.76)$ & 17.04 & $(5.11)$ & 16.34 & $(5.63)$ \\
\hline 2-day & 22.71 & $(7.57)$ & 18.39 & $(5.84)$ & 17.49 & $(7.38)$ \\
\hline \multicolumn{7}{|l|}{ SWLS } \\
\hline 6-week & 21.21 & $(7.43)$ & 23.62 & $(6.21)$ & 24.96 & $(6.80)$ \\
\hline 2-day & 20.63 & $(7.25)$ & 22.20 & $(7.41)$ & 23.45 & $(6.25)$ \\
\hline
\end{tabular}

For mindfulness (MAAS), quality of life (reverse scored) (AQoL), subjective well-being (PWI), positive and negative affect (PANAS) and life satisfaction (SWLS).

\section{Study 2}

\section{Method}

To investigate what unique difference the full Mindfulnessbased Quality of Life and Well-Being Program (MQW) might have in comparison to teaching just mindfulness alone, a follow up study was conducted comparing the full 6-week version of the MQW program to the mindfulness section of the program (the first 2-weeks of the full program with an additional 4 weeks of practise). To maintain program integrity, the same content was taught in both conditions; however, in the mindfulness alone section, the frequency and duration of times to practise the exercises were extended to expand the 2 -week section to the same 6 week period.

\section{Participants}

The recruitment methods used in study 1 (online university student portals and snowball sampling techniques), participant selection criteria (a minimum of eighteen years old, not a reported dependency on medical or psychiatric care, provision of informed consent), and randomisation procedures, were also used in study 2 .
Table 6 Intention to Treat prepost-follow $\mathrm{F}$ ratios for 6-week $(\mathrm{n}=53)$ and 2-day $(\mathrm{n}=49)$

\begin{tabular}{|c|c|c|c|c|c|c|c|}
\hline \multirow[b]{2}{*}{ Measure } & \multirow[t]{2}{*}{ GROUP } & \multicolumn{3}{|l|}{ TIME } & \multicolumn{3}{|c|}{ GROUP x TIME } \\
\hline & & pre-pst-fw & pre-pst & pst-fw & pre-pst-fw & pre-pst & pst-fw \\
\hline Multivariate & .97 & 25.99 & $29.79 * * *$ & $5.37 * * *$ & 1.04 & .58 & 1.31 \\
\hline MAAS & $4.11^{*}$ & $57.51 * * *$ & $42.31 * * *$ & $23.21 * * *$ & 1.68 & 1.13 & $4.94 *$ \\
\hline AQoL & 3.39 & $53.93 * * *$ & $58.84 * * *$ & $8.57 * *$ & 1.07 & 1.10 & 2.92 \\
\hline PWI & .77 & $4.21^{*}$ & $7.58 * *$ & .90 & .35 & .66 & .23 \\
\hline PA & 2.19 & $36.67 * * *$ & $46.64 * * *$ & 1.71 & .26 & .51 & .08 \\
\hline NA & 2.76 & $22.41 * * *$ & $21.57 * * *$ & 3.86 & .50 & .42 & .13 \\
\hline SWLS & .89 & $21.03 * * *$ & $16.19 * * *$ & $7.89 * *$ & .51 & .72 & .01 \\
\hline
\end{tabular}

For mindfulness (MAAS), quality of life (AQoL), subjective well-being (PWI), positive and negative affect (PANAS) and life satisfaction (SWLS) $(* p<0.05, * * p<0.01, * * * p<0.001)$. 
MAAS treatment vs control pre-post-follow up mean scores

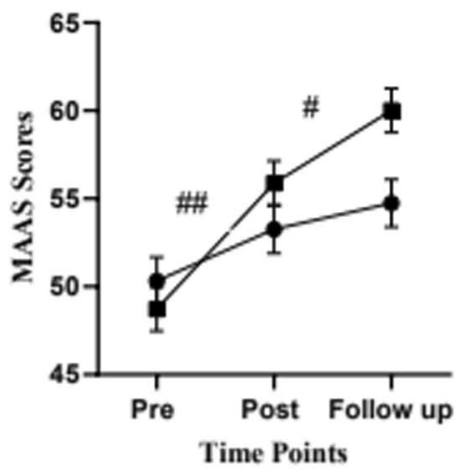

PWI treatment vs control pre-post-follow up mean scores

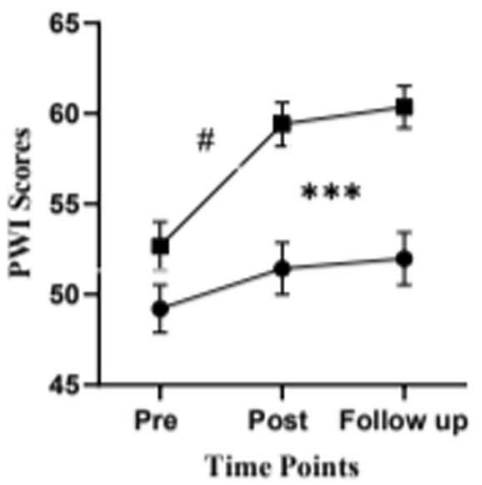

NA treatment vs control pre-post-follow up mean scores

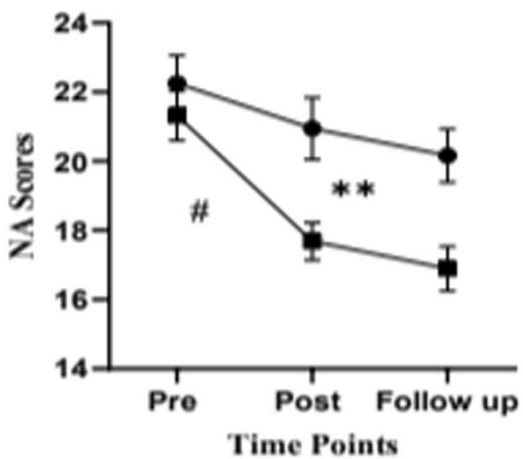

Fig. 1 Intention to treat treatment $(n=102)$ and control $(n=89)$ prepost-follow up scores. For mindfulness (MAAS), quality of life (reverse scored) (AQoL), subjective well-being (PWI), positive and negative affect (PANAS) and life satisfaction (SWLS). Error bars rep-

\section{Assessment}

Four instruments were chosen to assess the intervention (see Appendix B) and data was again collected across the three time periods (pre, post and follow up), with analyses done on summed change scores (pre-test score minus post-test score and post-test score minus follow up-test score). The previously mentioned Clinical Quality of Life
AQoL treatment vs control pre-post-follow up mean scores

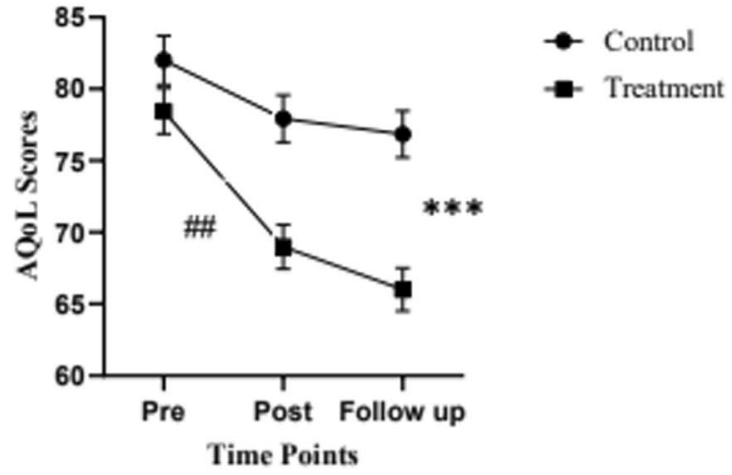

PA treatment vs control pre-post-follow up mean scores

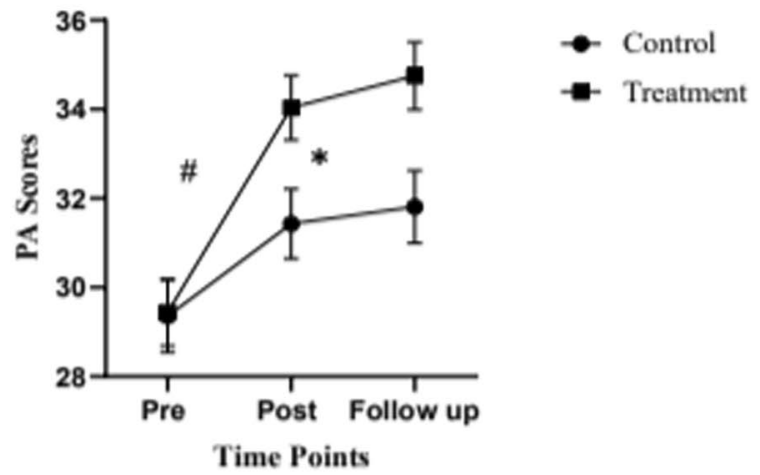

SWLS treatment vs control pre-post-follow up mean scores

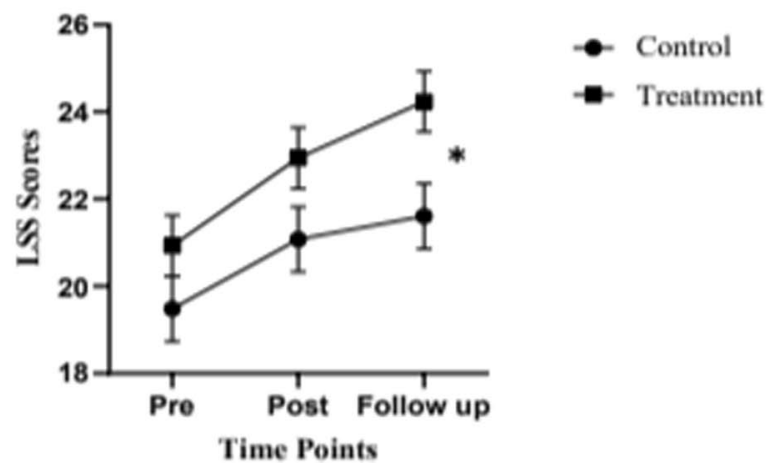

resent standard errors. \# indicates a pre-post or post-follow up difference and $*$ indicates a difference between treatment and control $(\# p<$ $\left.0.05, \# \# p<0.01, * p<0.05,{ }^{* *} p<0.01, * * * p<0.001\right)$

Scale (CLINQOL), Satisfaction with Life scale (SWLS) and the Positive and Negative Affect Schedule (PANAS) were chosen to evaluate change in quality of life and subjective well-being, and to assess possible clinical changes in mental health, the abbreviated Depression, Anxiety and Stress Scale (DASS-21) was also added. The DASS21 correlates with other clinical measures of depression and anxiety (Coker et al., 2018) and internal consistency 
MAAS 6-week and 2-day pre-post-follow up mean scores

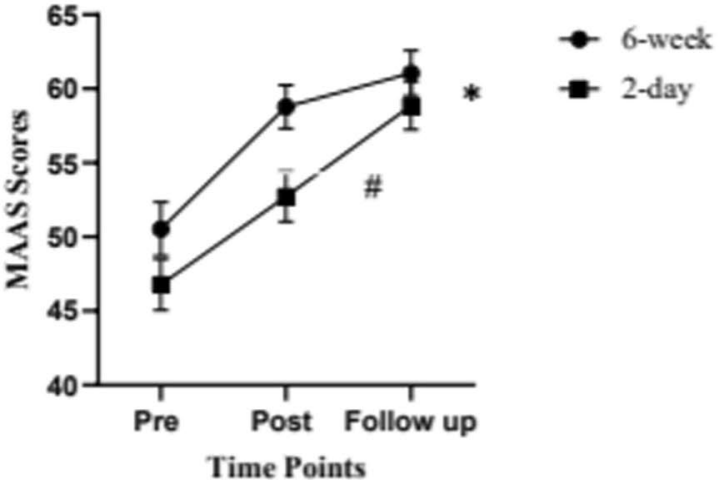

PWI 6-week and 2-day pre-post-follow up mean scores

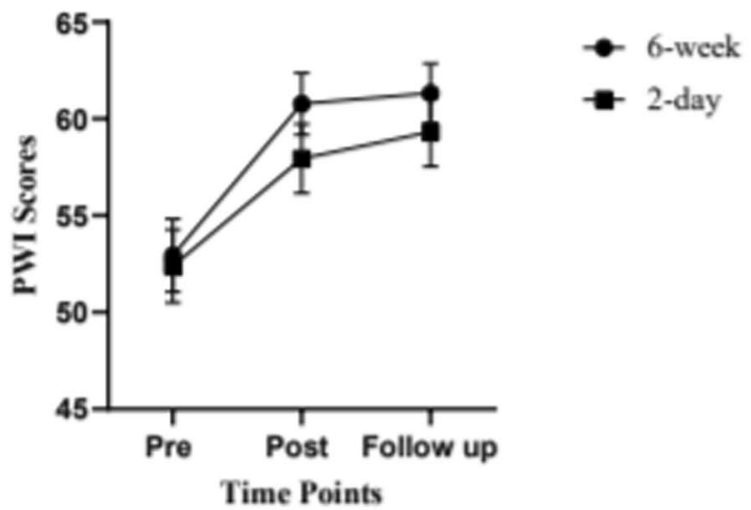

NA 6-week and 2-day pre-post-follow up mean scores

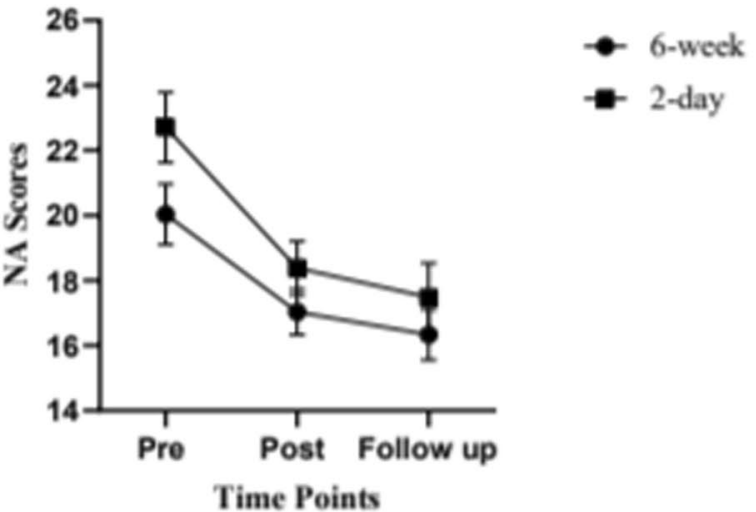

Fig. 2 Intention to treat 6 -week $(n=53)$ and 2-day $(n=49)$ pre-postfollow up scores. For mindfulness (MAAS), quality of life (reverse scored) (AQoL), subjective well-being (PWI), positive and negative affect (PANAS) and life satisfaction (SWLS). Error bars represent

reliability amongst non-clinical adult samples is acceptable for all scales (Cronbach's alpha is .91, .80, and .84 for Depression, Anxiety, and Stress respectively) (Sinclair et al., 2011).
AQoL 6-week and 2-day pre-post-follow up mean scores

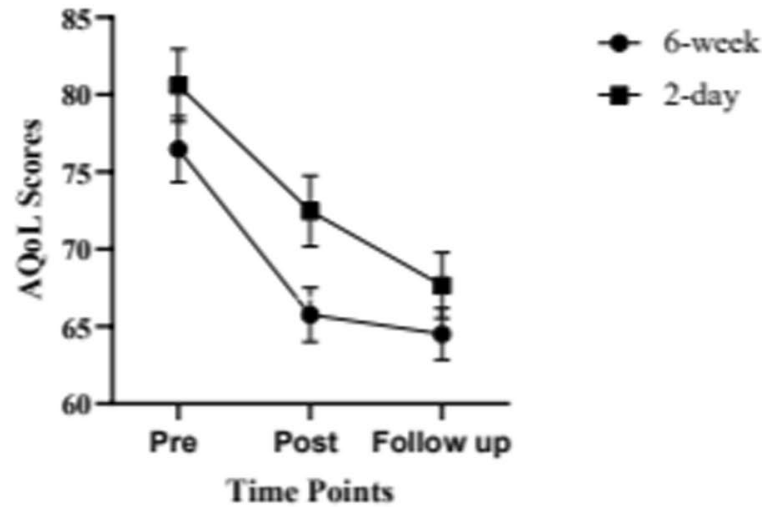

PA 6-week and 2-day pre-post-follow up mean scores

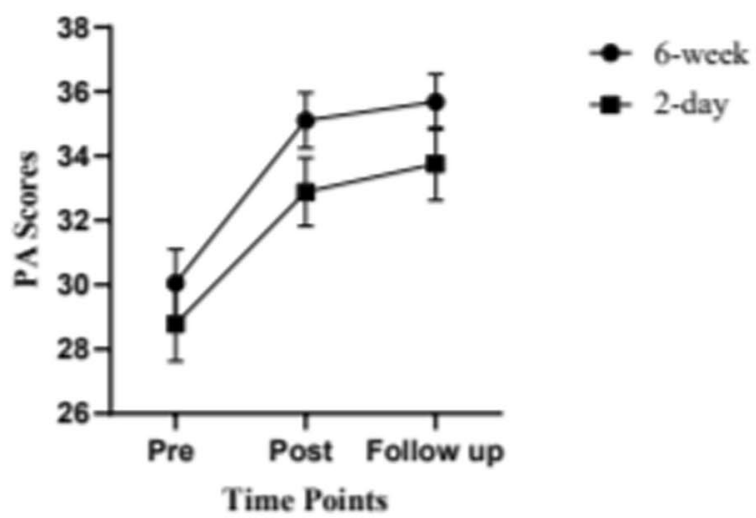

SWLS 6-week and 2-day pre-post-follow up mean seores

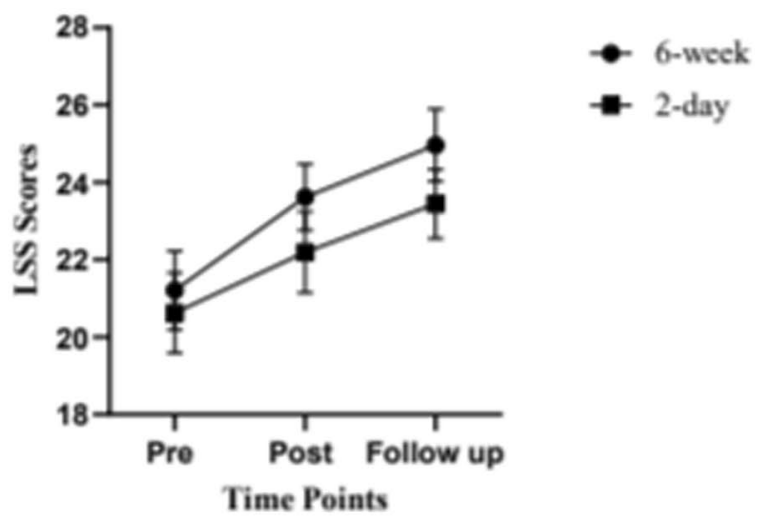

standard errors. \# indicates a post-follow up difference and * indicates a difference between treatment and control $\# p<0.05$, $* p<$ $0.05, * * p<0.01)$

\section{Procedure}

Treatment fidelity was managed with the content for both programs being delivered by university educated trainers 
Table 7 Raw scores $(n=42)$ and intention to treat $(n=59)$ pre and post mean scores and t-tests results of 2 day treatment group for quality of life (CLINQOL) $(* * * p<0.001)$

\begin{tabular}{llllll}
\hline Measure & Pre & & Post & \\
\cline { 2 - 3 } & $(S D)$ & & $\mathrm{M}$ & $(S D)$ & $\mathrm{t}$ \\
\hline
\end{tabular}

CLINQOL

$\begin{array}{llllll}\text { Raw score } & 288.24 & (53.91) & 322.14 & (53.17) & -5.177 * * *\end{array}$

Intention to treat $290.73 \quad(56.90) \quad 314.86 \quad(57.44) \quad-4.766 * * *$

who had previous experience in delivering the full MQW. The two conditions were run simultaneously within a 6 week period, and the evaluation surveys were completed for the both the MQW and the mindfulness program at the same pre, post and follow up time points (Pre $=0$ weeks, Post $=$ 6 weeks and Follow up $=10$ weeks). Data was collected on location, at the beginning and end of treatment, and online for follow up.

An initial sample of 127 subjects registered online for the program and were randomly allocated into the two conditions (Mindfulness-based Quality of Life and Well-Being program and Mindfulness training only), and 106 subjects presented at session 1 to complete the pre-test. The age range was $18-77$ years and a median age of 42.1 years with $88 \%$ females and $12 \%$ males. A total of 74 subjects $(\mathrm{MQW}=45$, Mindfulness $=29)$ began the program and filled out assessments across the three time periods. Of those who entered the program, 28 people did not complete at least 4 sessions of the six week program. As the completion criterion for sufficient program content exposure was defined as 4-6 sessions, these participant scores were trimmed, leaving a total of 46 participants $(\mathrm{MQW}=26$, Mindfulness $=20$ ).

\section{Results}

Prior to conducting the analyses, a skewness analysis revealed all variables to be normally distributed with no significant outliers. A correlation analysis revealed significant relationships among dependent variables, so MANOVA was conducted across the pre, post and follow up time points. For univariate effects, planned contrasts (pre-post
Table 8 Intention to Treat mean scores at pre, post, and follow up for full MQW Program $(\mathrm{n}=26)$ and Mindfulness Section only $(n=20)$ participants

\begin{tabular}{|c|c|c|c|c|c|c|}
\hline \multirow[t]{2}{*}{ Measure } & \multicolumn{2}{|l|}{ Pre } & \multicolumn{2}{|l|}{ Post } & \multicolumn{2}{|c|}{ Follow up } \\
\hline & M & $(S D)$ & M & $(S D)$ & M & $(S D)$ \\
\hline \multicolumn{7}{|l|}{ PA } \\
\hline MQW & 30.00 & $(8.42)$ & 33.46 & $(8.20)$ & 32.00 & $(8.48)$ \\
\hline Mindfulness & 27.00 & $(8.08)$ & 31.95 & $(7.38)$ & 30.85 & $(8.21)$ \\
\hline \multicolumn{7}{|l|}{ NA } \\
\hline MQW & 20.88 & $(7.95)$ & 18.88 & (7.48) & 19.46 & $(8.04)$ \\
\hline Mindfulness & 24.55 & $(8.76)$ & 18.45 & $(6.37)$ & 18.70 & $(6.70)$ \\
\hline \multicolumn{7}{|l|}{ SWLS } \\
\hline MQW & 21.96 & $(7.52)$ & 23.69 & $(7.52)$ & 24.04 & $(8.02)$ \\
\hline Mindfulness & 20.20 & $(7.12)$ & 22.75 & $(5.54)$ & 23.10 & $(5.47)$ \\
\hline \multicolumn{7}{|l|}{ DASS-D } \\
\hline MQW & 4.35 & $(4.57)$ & 3.12 & $(2.96)$ & 3.31 & $(3.16)$ \\
\hline Mindfulness & 7.90 & $(5.83)$ & 3.60 & $(3.48)$ & 3.8 & $(3.95)$ \\
\hline \multicolumn{7}{|l|}{ DASS-A } \\
\hline MQW & 4.19 & $(4.57)$ & 3.81 & $(4.50)$ & 3.69 & $(4.53)$ \\
\hline Mindfulness & 6.25 & $(5.77)$ & 3.85 & $(4.49)$ & 3.40 & $(4.75)$ \\
\hline \multicolumn{7}{|l|}{ DASS-S } \\
\hline MQW & 7.77 & $(5.88)$ & 6.27 & $(5.07)$ & 6.42 & $(5.23)$ \\
\hline Mindfulness & 9.20 & $(5.52)$ & 6.05 & $(4.49)$ & 5.90 & $(4.56)$ \\
\hline \multicolumn{7}{|l|}{ DASS-21 } \\
\hline MQW & 16.31 & $(12.92)$ & 13.19 & (10.94) & 13.42 & $(11.1)$ \\
\hline Mindfulness & 23.35 & $(15.53)$ & 13.50 & (11.16) & 13.10 & (11.75) \\
\hline \multicolumn{7}{|l|}{ CLINQOL } \\
\hline MQW & 320.38 & $(65.58)$ & 348.04 & (70.76) & 350.19 & (69.18) \\
\hline Mindfulness & 287.50 & $(48.85)$ & 329.55 & $(59.18)$ & 329.30 & (46.97) \\
\hline
\end{tabular}

For quality of life (CLINQOL), subjective well-being (SWLS), positive and negative affect (PANAS) and mental health (DASS-21, DASS-D, DASS-A, DASS-S). 
Table 9 Intention to treat pre-post and post-follow up change scores correlational matrix for MQW and mindfulness only $(n=46)$

\begin{tabular}{llllll}
\hline & PA & NA & SWLS & DASS & CLINQOL \\
\hline $\begin{array}{lllll}\text { Pre-post } \\
\text { PA }\end{array}$ & 1 & & & & \\
NA & $-.504 * *$ & 1 & & & \\
SWLS & $-.647 * *$ & $-.390 * *$ & 1 & & \\
DASS & $.597 * *$ & $.654 * *$ & $-.584 * *$ & 1 & \\
CLINQOL & $-.592 * *$ & -.240 & $.494 * *$ & $-.334^{*}$ & 1 \\
Post-Follow up & & & & & \\
PA & 1 & & & & \\
NA & $-.671 * *$ & 1 & & & \\
SWLS & .258 & $-.432 * *$ & 1 & & \\
DASS & $-.387 * *$ & $.390 * *$ & $-.395 * *$ & 1 & \\
CLINQOL & .212 & -.099 & .043 & $-.381 * *$ & 1 \\
\hline
\end{tabular}

For quality of life (CLINQOL), subjective well-being (SWLS), positive and negative affect (PANAS) and mental health (DASS) $(* * p<$ $0.01)$.

and post-follow up) were run to clarify interactions and, if significant, t-tests were conducted within each condition at pre, post and follow up and between conditions at each time point. Intention to treat (last score carried forward for missing values) analyses are presented for completers (analyses limited to participants with complete data again provided no new information). Descriptive statistics, correlations between dependent variables, results from multivariate and univariate analyses, and t-tests are summarised in Tables 8 , 9 and 10.

\section{MQW Versus Mindfulness Only Intention to Treat Data}

Multivariate analyses revealed an effect across time but no effect between groups or an interaction between group and time (Table 10). Univariate analyses revealed that the mindfulness only participants demonstrated improvements in primarily the clinical indicators of negative affect, anxiety and overall mental health (DASS-21) along with quality of life (CLINQOL), compared to their MQW counterparts. This may indicate that extra time allocated for mindfulness exercises over psycho-education produces greater change (Fig. 3).

\section{Discussion}

The purpose of this study was to develop and test, with a random sample from the general population, a new quality of life and well-being enhancement program. By examining the effect upon six dependent variables that, based on prior research and theory, were predicted to be modified by such interventions, the research sought to explore the efficacy of the newly developed Mindfulness-based Quality of Life and Well-being Program (MQW).

Presented in both a six week graduated format and two day intensive format, the main hypothesis was that the program would improve scores in comparison to waitlist control, across the six dependent variables of mindfulness, quality of life, subjective well-being, positive and negative affect and life satisfaction. This hypothesis was supported with analysis of the data revealing that there were significant differences for treatment versus control in five of the six variables (except life satisfaction) at post-test. Differences between groups were maintained at follow up for most variables and strengthened for mindfulness. These findings were further strengthened by significant pre-post gains as measured by the new Clinical Quality of Life Scale (CLINQOL).

The intervention content was presented in three sections: mindfulness training; psycho-education and goal setting in life areas associated with quality of life; and psycho-education and exercises to improve well-being. The aim was to train participants in these three areas and to determine whether participants reported any changes. Significant
Table 10 Intention to Treat pre-post-follow $\mathrm{F}$ ratios for full MQW Program $(n=26)$ and Mindfulness Section only $(\mathrm{n}=20)$ participants

\begin{tabular}{|c|c|c|c|c|c|c|c|}
\hline \multirow[b]{2}{*}{ Measure } & \multirow[t]{2}{*}{ GROUP } & \multicolumn{3}{|l|}{ TIME } & \multicolumn{3}{|c|}{ GROUP x TIME } \\
\hline & & pre-pst-fw & pre-pst & pst-fw & pre-pst-fw & pre-pst & pst-fw \\
\hline Multivariate & .99 & $3.50 * *$ & $6.35 * * *$ & 1.56 & 1.29 & 1.84 & .39 \\
\hline PA & .76 & $10.32 * * *$ & $13.25 * * *$ & $4.51 *$ & .53 & .41 & .90 \\
\hline NA & .16 & $17.13 * * *$ & $18.01 * * *$ & 1.12 & $5.25 * *$ & $4.61 *$ & .17 \\
\hline SWLS & .40 & $6.66^{* *}$ & $5.82 *$ & 2.45 & .21 & .21 & .00 \\
\hline DASS-D & .03 & $14.69 * * *$ & $19.99 * * *$ & .74 & 2.25 & $6.16^{*}$ & .00 \\
\hline DASS-A & .47 & $23.76 * * *$ & $8.67 * *$ & 1.95 & $6.97 * *$ & $4.54^{*}$ & .68 \\
\hline DASS-S & 2.01 & $24.98 * * *$ & $15.25 * * *$ & .00 & .89 & 1.92 & .01 \\
\hline DASS-21 & 2.08 & $17.96 * * *$ & $23.01 * * *$ & .03 & $.59^{*}$ & $6.21^{*}$ & .50 \\
\hline CLINQOL & .20 & $10.99 * * *$ & $24.88 * * *$ & .09 & $5.52 *$ & 1.06 & .14 \\
\hline
\end{tabular}

For quality of life (CLINQOL), subjective well-being (SWLS), positive and negative affect (PANAS) and mental health ((DASS-21, DASS-D, DASS-A, DASS-A).) $\left({ }^{*} p<0.05, * * p<0.01, * * * p<0.001\right)$ 
findings specifically in the mindfulness, quality of life and subjective well-being measures give some indication of program efficacy and suggest that the program achieved its aims.

With respect to each specific component of the program, in the mindfulness training section participants were introduced to ten mindfulness attributes and trained in exercises to improve these characteristics. Progress was borne out at both post treatment and follow up against control, suggesting that this method is an effective means to improve self-report of mindfulness as reported using Brown and Ryan's (2003) mindfulness scale.

In the quality of life section, participants were taught how to improve five quality of life domains (relationships, work,

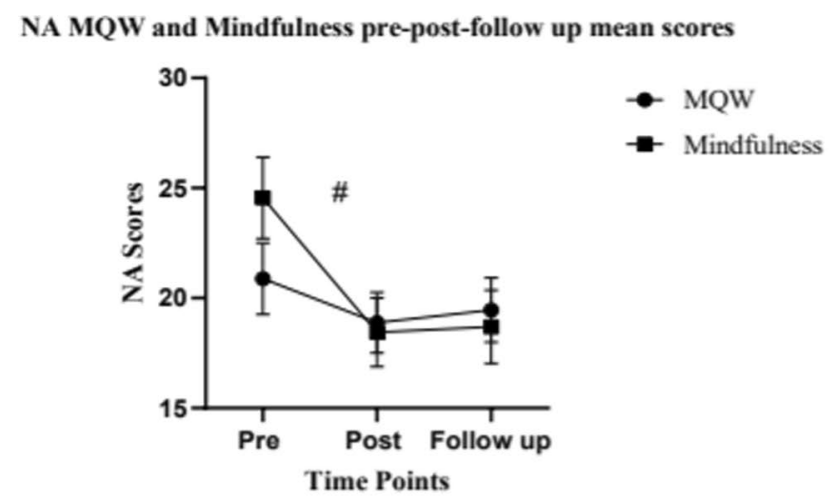

DASS-A MQW and Mindfulness pre-post-follow up mean scores

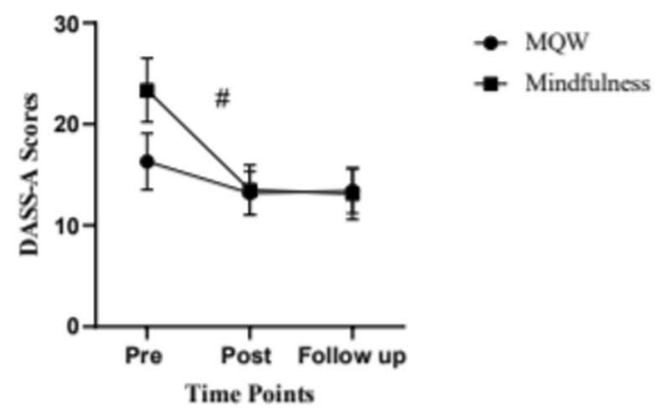

CLINQOL MQW and Mindfulness pre-post-follow up mean scores

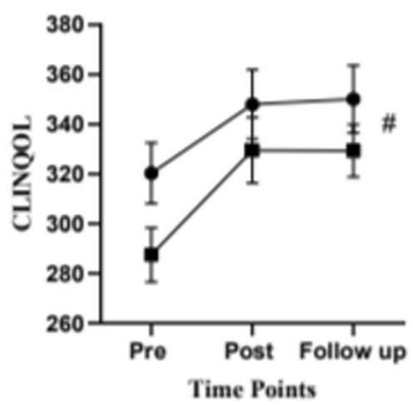

Fig. 3 Intention to treat full MQW Program $(n=26)$ and Mindfulness Section only $(n=20)$ participants. For quality of life (CLINQOL), subjective well-being (SWLS), positive and negative affect (PANAS) money, health and leisure) (Diener et al., 1999; Tay et al., 2014), and then were taught to write and execute short and long term goals using time-framed strategies to assist goal achievement. One could speculate that significant increases in the Quality of Life Index scores (Richardson et al., 2013) offer further evidence that goal setting has some bearing on increased perception of quality of life (Deci \& Ryan, 2000; Locke \& Latham, 2013).

Finally, in the well-being section participants received psycho-education on the origins of self-esteem and wellbeing and completed exercises to build well-being. Participants aimed to achieve this independent of the status of the objective life domains in section two that were previously worked on.

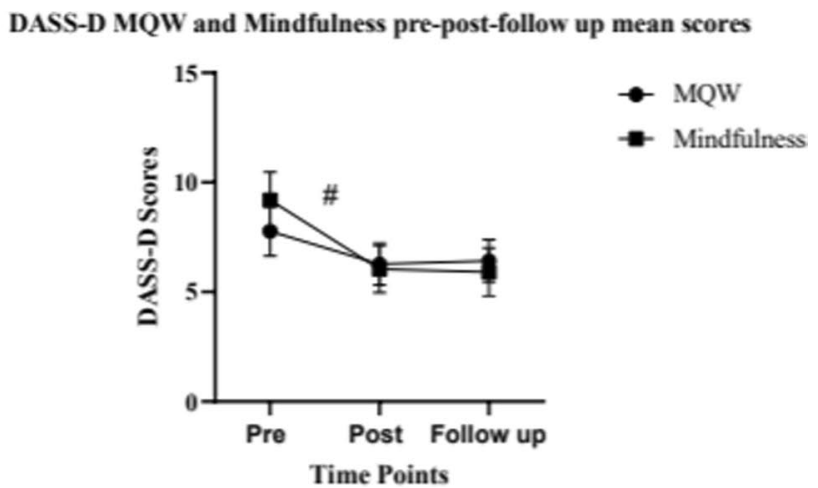

DASS-21 MQW and Mindfulness pre-post-follow up mean scores

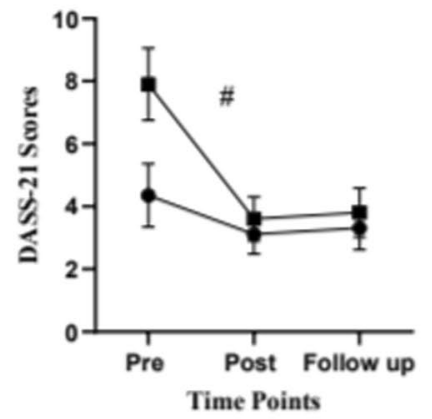

and mental health (DASS-21, DASS-D and DASS-A). Error bars represent standard errors and \# indicates a pre-post or pre-post-fw difference $(\# p<0.05)$ 
The reported increases in the Personal Wellbeing Index (PWI-A, International Wellbeing Group, 2006) and in the Positive Affect and Negative Affect measures (PANAS) (Watson et al., 1988) indicate successful uptake of the program. Of interest, however, is why the well-researched Satisfaction with Life scale (Diener et al., 1985; Pavot \& Diener, 2009) did not show signs of improvement. One possibility is that life satisfaction captures only one dimension of subjective well-being - the cognitive evaluation of an individual's satisfaction with their life. As this scale describes an enduring trait it may not be amenable to change after a six week or two day intervention, although life satisfaction is thought to be sensitive to clinical interventions (Pavot \& Diener, 1993, 2009). By contrast, significant findings in the more multidimensional Quality of Life Index (Richardson et al., 2013) and Personal Wellbeing Index (International Wellbeing Group, 2006) lend support to the inclusion of measures that capture a broader picture of each construct.

As the program was made up of discrete sections that focused on different topics, it is difficult to identify which components had most impact. For example, would mindfulness training alone (Hölzel et al., 2011) be sufficient to create the reported gains in quality of life and well-being, or was the addition of the quality of life goal setting and well-being training pivotal in that result? Brown et al. (2009) reasoned that mindfulness could reduce the "achievementaspiration gap" (the bigger the gap between expectations and outcomes, the lower the evaluation of one's quality of life) by assisting someone to "want what one has," which in turn leads to an increase in the perception of quality of life. Hence, mindfulness training may have been key to the success of this program.

In support of the notion that mindfulness training can improve existing happiness programs, Smith, Compton and West (Smith et al., 1995) found that the addition of meditation to Fordyce's $(1983,1988)$ happiness enhancement program resulted in a further improvement in dependent measures in comparison to the original group. However, as mindfulness now has a strong presence in the intervention literature, a richer exploration of the constructs and processes that are proposed to be responsible for well-being outcomes could have benefit for future intervention design.

For example, as the third section of the program focused on the role in well-being of self-concept (Hutz et al., 2014), positive self-esteem (Robins et al., 2001), and internal locus of control (Strickland, 2016), a more in-depth inquiry into how the concept of the self impacts the perception of quality of life could prove useful for future programs. As such, it could build on the extension suggested in traditional mindfulness (Kudesia \& Nyima, 2014) to cultivate the non-dual, non-self referencing experience (Natarajan, 2000; Vago \& Silbersweig, 2012). In view of its reduced focus on selfregulation (Lutz et al., 2008; Raffone \& Srinivasan, 2009), this may be associated with more robust and enduring experiences of well-being and generate a more resourceful response to life conditions. Such an exploration could feed back to the quality of life and well-being research and impact the development of interventions.

In terms of different intervention delivery formats, previous research suggesting that there is little difference between compressed and progressive learning formats (Arrey, 2005; Wlodkowski \& Westover, 1999) was again borne out in this study. The two-day group improved more from post-treatment to follow-up in mindfulness than the 6-week group; however, this increase brought them in line with the 6 -week group at follow-up. This seems reasonable as at post-test the two-day group had only just been taught the ten mindfulness skills, whilst the six-week group had already practised these skills over the previous six weeks leading up to post-test.

The two-day group's improvement over the following four weeks, in comparison to the six-week group who had already achieved most of their gains, does, however, support the evidence that people benefit from time to practice mindfulness (Cahn et al., 2013; Cullen, 2011). Whilst these outcomes suggest that current research on program design appears to generalise to a well-being enhancement setting, in view of resource allocation (participant time and training budgets), this area deserves further investigation.

Non-completers who provided data at post-treatment and/ or follow-up (22 participants) received no beneficial effect from completing either one to three sessions of the six-week program or only one day of the two-day program. This finding is of interest and seems to be in line with research that people need to practise meditation on a regular basis to receive any sustained benefit (Delmonte, 1985; Jones, 2018; Zettle \& Gird, 2016). However, there may be a motivational factor involved in this outcome, in that most of the six-week completer cohort (minimum attendance was four out of a possible six sessions) who missed one or two sessions still completed the final session, suggesting some level of commitment to completing the process. In contrast, no participant who attended three or fewer classes attended the final session, suggesting a possible lack of engagement or motivation, a variable found to be predictive of success (Locke \& Schattke, 2018).

As the primary interest in the analysis of the program was its efficacy, a waitlist control condition was chosen as it provided an untreated comparison for the active experimental group. However, a limitation of choosing a waitlist control over an established program serving as an active comparator is that is remains unclear if the newly developed program is superior compared to other programs. As such, in future studies, the Mindfulness-based Quality of Life and Well-being Program (MQW) should be compared against administration of programs such as the Mindfulness-based Stress Reduction program (MBSR). 
In support of Van Dam et al.'s (Van Merriënboer \& Kirschner, 2017) critique that only $1 \%$ of research has been done outside of research contexts, the follow up community study, that compared the full MQW program to an expanded version of the mindfulness section, gave further information on the influential role that exercises may play in content uptake. As the mindfulness only section with its increased time to practice proved more effective than the full program in decreasing negative affect and other mental health measures, further iterations of the full program could do well to increase time allocated to practise the skillsets being taught in the psycho-education portions of the program.

In terms of evaluation of adverse effects (Compson, 2018), there may have been an optimism bias in the evaluation of the program, in that it sought to determine its efficacy alone rather than its potential harm. This was partially addressed in a brief program evaluation-questionnaire that included the question "Overall what were the least useful features of the program for you?". However as there are no reliable estimates of harm due to mindfulness-based interventions (Baer et al., 2019), it would have been of value to identify any adverse effects due to exposure to the trial of a new program. For example, participants could have been evaluated for increased symptoms after treatment (Hirshberg et al., 2020) using the Global Severity Index (GSI), which examines psychological symptom severity (Derogatis, 2012). Furthermore, participants who dropped out during the program could have been sent an evaluation questionnaire that sought to address these questions.

In respect of the evaluation process itself, intervention efficacy rested on standardised self-report scales and the newly developed Clinical Quality of Life Scale (CLINQOL). Whilst self-report is the most common and easiest modality to assess intervention effects, other forms of measurement could have provided richer data to reduce false optimism, social desirability biases or the halo effect (Deaton, 2018). For example, the collection of behavioural data (Levinson et al., 2014) such as frequency and duration of practice during training could assist a richer evaluation of effects amongst participants. Similarly, inclusion of more eudaimonic scales such as Peterson et al.'s (2005) Orientations to Happiness Questionnaire, or the Scales of Psychological Well-Being (Ryff, 1989) which includes self-acceptance, purpose in life, personal growth and development dimensions, could also have yielded interesting data.

As the literature on subjective wellbeing and mindfulness has been criticised for insufficient construct and criterion validation of measures (Lepper, 1998; Van Dam et al., 2010), it could have also been of value to include observer or other reports (Ashton, 2013). For example, a brief scale could have been added to the overall survey to be completed by both participant and a friend or family member at pre, post and follow-up. In addition, data on months/years of meditation or mindfulness practice (Hauswald et al., 2015; van Leeuwen et al., 2009) at pre-test could also be gathered and correlated with scores on Brown and Ryan's (2003) Mindfulness Attention Awareness Scale.

Whilst acknowledging the phenomenon of attrition in any program delivery, there could be some provision for follow-up after missed sessions to preserve participation. It is possible that a non-coercive follow-up reminder to participants who missed sessions may encourage increased participation in the program which, in turn, would increase sample size and power in the analysis. Finally, a way of adding to the richness of the intervention, along with homework given at the end of each training section, could be to collect, evaluate and return homework as an opportunity to give more personalised feedback to participants.

It is of relevance, in line with a current critique within the mindfulness research, to note that the current MQW intervention falls more into a second-generation mindfulness-based intervention (SG-MBI) than a first generation mindfulness-based intervention (FG-MBI) as described by Van Gordon, Shonin and Griffiths (Van Gordon et al., 2015; Van Gordon \& Shonin, 2020). Key differences relevant to the MQW and its focus on quality of life is that, in line with SG-MBIs, practitioners employ not only 'non-judge-mental' awareness (a key FG-MBI mindfulness descriptor), but also encourage an active participation in the present moment and to respond in an adaptive manner.

As SG-MBIs also teach mindfulness along with other meditative practices and principles (impermanence of phenomena, emptiness/non-self, and loving-kindness meditations) (Shonin et al., 2014), the current intervention, with its suite of mindfulness and well-being methods, aimed to assist in the development of this next exciting stage of mindfulness-based interventions.

Overall, these findings suggest that the hybrid program (mindfulness, goal setting and psycho-education) was effective in improving mindfulness, quality of life, subjective well-being and positive and negative affect. Such results provide preliminary evidence that a multi-dimensional training approach that teaches mindfulness, goal setting and well-being enhancement, and that includes both psycho-education and skills training can be a valuable and effective intervention model. This broader type of curriculum may be able to offer participants the opportunity to not only learn mindfulness and goal setting skills but in doing so, learn both the theory to develop well-being and quality of life and the exercises to assist in its achievement and maintenance.

The datasets generated during and/or analysed during the current study are available from the corresponding author on reasonable request. 
Supplementary Information The online version contains supplementary material available at https://doi.org/10.1007/s12144-021-02672-w.

Authors Contribution Material preparation, data collection and analysis was performed by Patrick Jones. The first draft of the manuscript was written by Patrick Jones and all authors commented on previous versions of the manuscript. All authors read and approved the final manuscript.

Funding Open Access funding enabled and organized by CAUL and its Member Institutions. The authors received no financial support for the research, authorship, and/or publication of this article.

\section{Declarations}

Conflict of Interests The authors declared no potential conflicts of interest with respect to the research, authorship, and/or publication of this article.

Ethics All human studies have been approved by the appropriate ethics committee and have been performed in accordance with the ethical standards laid down in the 1964 Declaration of Helsinki and its later amendments.

Consent All persons gave their informed consent prior to their inclusion in the study.

Open Access This article is licensed under a Creative Commons Attribution 4.0 International License, which permits use, sharing, adaptation, distribution and reproduction in any medium or format, as long as you give appropriate credit to the original author(s) and the source, provide a link to the Creative Commons licence, and indicate if changes were made. The images or other third party material in this article are included in the article's Creative Commons licence, unless indicated otherwise in a credit line to the material. If material is not included in the article's Creative Commons licence and your intended use is not permitted by statutory regulation or exceeds the permitted use, you will need to obtain permission directly from the copyright holder. To view a copy of this licence, visit http://creativecommons.org/licenses/by/4.0/.

\section{References}

Anderson, N. D., Lau, M. A., Segal, Z. V., \& Bishop, S. R. (2007). Mindfulness-based stress reduction and attentional control. Clinical Psychology \& Psychotherapy, 14, 449-463.

Argyle, M. (1999). Causes and correlates of happiness. Chapter 18. In D. Kahneman, E. Diener, \& N. Schwarz (Eds.), (1999). WellBeing: the foundations of Hedonic Psychology (pp. 353-373). New York: Russell Sage Foundation.

Arrey, L. N. (2005). Intensive Learning Versus Traditional Learning in Organic Chemistry. Summer Academe, 5. https://doi.org/10. 5203/sa.v5i0.344

Baer, R., Crane, C., Miller, E., \& Kuyken, W. (2019). Doing no harm in mindfulness-based programs: Conceptual issues and empirical findings. Clinical Psychology Review, 71, 101-114. https://doi. org/10.1016/j.cpr.2019.01.001

Baer, R. A., Smith, G. T., Hopkins, J., Krietemeyer, J., \& Toney, L. (2006). Using self-report assessment methods to explore facets of mindfulness. Assessment, 13, 27-45.

Bakas, T., McLennon, S. M., Carpenter, J. S., Buelow, J. M., Otte, J. L., Hanna, K. M., et al. (2012). Systematic review of health-related quality of life models. Health and Quality of Life Outcomes, 10(1), 134. https://doi.org/10.1186/1477-7525-10-134

Boehm, J. K., \& Kubzansky, L. D. (2012). The heart's content: the association between positive psychological well-being and cardiovascular health. Psychological Bulletin, 138, 655-691.

Bonow, J. T., Maragakis, A., \& Follette, W. C. (2012). The challenge of developing a universal case conceptualization for Functional Analytic Psychotherapy. International Journal of Behavioral Consultation and Therapy, 7(2-3), 2-8. https://doi.org/10.1037/ h0100930

Brackertz, N. (2013). The Impact of Financial Counselling on Alleviating Financial Stress in Low Income Households: A National Australian Empirical Study. Social Policy and Society, 13(3), 389-407. https://doi.org/10.1017/s1474746413000511

Brannan, D., Biswas-Diener, R., Mohr, C. D., Mortazavi, S., \& Stein, N. (2012). Friends and family, a cross-cultural investigation of social support and subjective well-being. Journal of Positive Psychology, 8, 65-75.

Brazier, J., \& Tsuchiya, A. (2015). Improving Cross-Sector Comparisons: Going Beyond the Health-Related QALY. Applied Health Economics and Health Policy, 13(6), 557-565. https://doi.org/ 10.1007/s40258-015-0194-1

Brewer, J. A., Worhunsky, P. D., Gray, J. R., Tang, Y., Weber, J., \& Kober, H. (2011). Meditation experience is associated with differences in default mode network activity and connectivity. Proceedings of the National Academy of Sciences, 108(50), 20254-20259.

Brown, K. W., \& Ryan, R. M. (2003). The benefits of being present: Mindfulness and its role in psychological well-being. Journal of Personality and Social Psychology, 84, 822-848.

Brown, K. W., Kasser, T., Ryan, R. M., Linley, P. A., \& Orzech, K. (2009). When what one has is enough: Mindfulness, financial desire discrepancy, and subjective well-being. Journal of Research in Personality, 43, 727-736.

Brown, T. C., Fry, M. D., \& Moore, E. W. G. (2017). A motivational climate intervention and exercise-related outcomes: A longitudinal perspective. Motivation Science, 3(4), 337-353. https://doi. org/10.1037/mot0000059

Brunstein, J. C. (1993). Personal goals and subjective well-being: A longitudinal study. Journal of Personality and Social Psychology, 65, 1061-1070.

Cahn, B. R., Delorme, A., \& Polich, J. (2013). Event-related delta, theta, alpha and gamma correlates to auditory oddball processing during Vipassana meditation. Social Cognitive and Affective Neuroscience, 8(1), 100-111.

Carr, D., Freedman, V. A., Cornman, J. C., \& Schwarz, N. (2014). Happy Marriage, Happy Life? Marital Quality and Subjective Well-being in Later Life. Journal of Marriage and Family, 76(5), 930-948. https://doi.org/10.1111/jomf.12133

Coker, A. O., Coker, O. O., \& Sanni, D. (2018). Psychometric properties of the 21-item Depression Anxiety Stress Scale (DASS-21). African Research Review, 12(2), 135. https://doi.org/10.4314/ afrrev.v12i2.13

Compson, J. (2018). Adverse Meditation Experiences: Navigating Buddhist and Secular Frameworks for Addressing Them. Mindfulness, 9(5), 1358-1369. https://doi.org/10.1007/ s12671-017-0878-8

Corten, P., Mercier, C., \& Pelc, I. (1994). "Subjective quality of life": Clinical model for assessment of rehabilitation in psychiatry. Social Psychiatry Psychiatric Epidemiology, 29, 178-183.

Cranny, C. J., Smith, P. C., \& Stone, E. F. (1992). Job satisfaction: How people feel about their jobs and how it affects their performance. Lexington.

Csíkszentmihályi, M. (2014). The Systems Model of Creativity: The Collected Works of Mihály Csíkszentmihályi. Springer. 
Cullen, M. (2011). Mindfulness-Based Interventions: An Emerging Phenomenon. Mindfulness, 2(3), 186-193. https://doi.org/10. 1007/s12671-011-0058-1

Cummins, R. A. (2003). Normative life satisfaction: Measurement issues and a homeostatic model. Social Indicators Research, 64, 159-190.

Cummins, R. A., Lau, A. L., \& Stokes, M. (2004). HRQOL and subjective well-being: noncomplementary forms of outcome measurement. Expert Review of Pharmacoeconomics \& Outcomes Research, 4(4), 413-420. https://doi.org/10.1586/14737167.4. 4.413

Curry, O. S., Rowland, L., Van Lissa, C. J., Zlotowitz, S., McAlaney, J., \& Whitehouse, H. (2018). Happy to Help? A systematic review and meta-analysis of the effects of performing acts of kindness on the well-being of the actor. https://doi.org/10.31219/osf.io/ytj5s

Czekierda, K., Horodyska, K., Banik, A., Wilhelm, L., Knoll, N., \& Luszczynska, A. (2019). Meaning in life and physical quality of life: Cross-lagged associations during inpatient rehabilitation. Rehabilitation Psychology. https://doi.org/10.1037/rep0000281

Dahiya, R., \& Rangnekar, S. (2019). Validation of the positive and negative affect schedule (PANAS) among employees in Indian manufacturing and service sector organisations. Industrial and Commercial Training, 51(3), 184-194. https://doi.org/10.1108/ ICT-08-2018-0070

De Boer, M. R., Waterlander, W. E., Kuijper, L. D., Steenhuis, I. H., \& Twisk, J. W. (2015). Testing for baseline differences in randomized controlled trials: an unhealthy research behavior that is hard to eradicate. International Journal of Behavioral Nutrition and Physical Activity, 12(1). https://doi.org/10.1186/ s12966-015-0162-z

Deci, E. L., \& Ryan, R. M. (2000). The "what" and "why" of goal pursuits: Human needs and the self-determination of behavior. Psychological Inquiry, 4, 227-268.

Delmonte, M. M. (1985). Meditation and anxiety reduction: A literature review. Clinical Psychology Review, 5, 91-102.

Demir, M., \& Weitekamp, L. A. (2007). I am so happy 'cause today I found my friend: Friendship and personality as predictors of happiness. Journal of Happiness Studies, 8, 181-211.

Denovan, A., \& Macaskill, A. (2016). Building resilience to stress through leisure activities: a qualitative analysis. Annals of Leisure Research, 20(4), 446-466. https://doi.org/10.1080/11745 398.2016.1211943

Derogatis, L. R. (2012). Derogatis Psychiatric Rating Scale. PsycTESTS Dataset. https://doi.org/10.1037/t15083-000

Diener E., \& Biswas-Diener, R. (2009) Will Money Increase Subjective Well-Being?: A Literature Review and Guide to Needed Research. In: Diener E. (eds) The Science of Well-Being. Social Indicators Research Series, vol 37. Springer, Dordrecht

Diener, E., Emmons, R. A., Larsen, R. J., \& Griffin, S. (1985). The Satisfaction With Life Scale. Journal of Personality Assessment, 49, 71-75.

Diener, E., Heintzelman, S. J., Kushlev, K., Tay, L., Wirtz, D., Lutes, L. D., \& Oishi, S. (2017). Findings all psychologists should know from the new science on subjective well-being. Canadian Psychology/Psychologie Canadienne, 58(2), 87-104. https://doi.org/ 10.1037/cap0000063

Diener, E., Inglehart, R., \& Tay, L. (2013). Theory and validity of life satisfaction scales. Social Indicators Research, 112, 497-527.

Diener, E., Suh, E. M., Lucas, R. E., \& Smith, H. L. (1999). Subjective well-being: Three decades of progress. Psychological Bulletin, 125(2), 276-302.

Dobkin, P. L., Irving, J. A., \& Amar, S. (2011). For Whom May Participation in a Mindfulness-Based Stress Reduction Program be
Contraindicated? Mindfulness, 3(1), 44-50. https://doi.org/10. 1007/s12671-011-0079-9

Dolan, P., Kudrna, L., \& Stone, A. (2016). The Measure Matters: An Investigation of Evaluative and Experience-Based Measures of Wellbeing in Time Use Data. Social Indicators Research, 134(1), 57-73. https://doi.org/10.1007/s11205-016-1429-8

Dreher, C. (2009). The Efficacy of Mindfulness-based Stress Reduction in Promoting Mindfulness, Psychological Health and Well-being. Curtin University of Technology School of Psychology.

Emmons, R. A. (2003). Personal goals, life meaning, and virtue: Wellsprings of a positive life. In C. L. M. Keyes \& J. Haidt (Eds.), Flourishing: Positive psychology and the life well-lived (pp. 105-128). American Psychological Association.

Estrada, E., Ferrer, E., \& Pardo, A. (2019). Statistics for Evaluating Pre-post Change: Relation Between Change in the Distribution Center and Change in the Individual Scores. Frontiers in Psychology, 9. https://doi.org/10.3389/fpsyg.2018.02696

Feldman, G., Greeson, J., \& Senville, J. (2010). Differential effects of mindful breathing, progressive muscle relaxation, and loving-kindness meditation on decentering and negative reactions to repetitive thoughts. Behaviour Research and Therapy, 48, $1002-1011$

Fishbach, A., \& Hofmann, W. (2015). Nudging self-control: A smartphone intervention of temptation anticipation and goal resolution improves everyday goal progress. Motivation Science, 1(3), 137-150. https://doi.org/10.1037/mot0000022

Folette, W. C., Linnerooth, P. J. N., \& Ruckstuhl, L. E. (2001). Positive psychology: A clinical behaviour analytic perspective. Journal of humanistic psychology, 41(1), 102-143.

Fordyce, M. W. (1983). A program to increase happiness: Further studies. Journal of counseling psychology, 30(4), 483-498.

Fordyce, M. W. (1988). A review of research on the happiness measures: A sixty second index of happiness and mental health. Social Indicators Research, 20, 355-381.

Freund, A. M., \& Baltes, P. B. (2002). The Adaptiveness of Selection, Optimization, and Compensation as Strategies of Life Management: Evidence From a Preference Study on Proverbs. The Journals of Gerontology Series B: Psychological Sciences and Social Sciences, 57(5), P426-P434. https://doi.org/10. 1093/geronb/57.5.p426

Gere, J., \& Schimmack, U. (2011). When romantic partners' goals conflict: Effects on relationship quality and subjective wellbeing. Journal of Happiness Studies, 14, 37-49.

Grouzet, F. M., Sheldon, K. M., Kasser, T., Ahuvia, A., Dols, J. M. F., Kim, Y., Lau, S., Ryan, R. M., Saunders, S., \& Schmuck, P. (2005). The structure of goals across 15 cultures. Journal of Personality and Social Psychology, 89, 800-816.

Hagerty, M. R., \& Veenhoven, R. (2003). Wealth and happiness revisited-growing national income does go with greater happiness. Social Indicators Research, 64, 1-27.

Halldorsdottir, T., \& Ollendick, T. H. (2016). Long-term outcomes of brief, intensive CBT for specific phobias: The negative impact of ADHD symptoms. Journal of Consulting and Clinical Psychology, 84(5), 465-471. https://doi.org/10.1037/ccp0000088

Hammer, J. H., Wade, N. G., \& Cragun, R. T. (2019). Valid Assessment of Spiritual Quality of Life With the WHOQOL-SRPB BREF Across Religious, Spiritual, and Secular Persons: A Psychometric Study. Psychology of Religion and Spirituality. https://doi.org/10.1037/re10000266

Hanley, A., Warner, A., \& Garland, E. L. (2014). Associations Between Mindfulness, Psychological Well-Being, and Subjective Well-Being with Respect to Contemplative Practice. 
Journal of Happiness Studies, 16(6), 1423-1436. https://doi. org/10.1007/s10902-014-9569-5

Hauswald, A., Übelacker, T., Leske, S., \& Weisz, N. (2015). What it means to be Zen: Marked modulations of local and interareal synchronization during open monitoring meditation. NeuroImage, 108, 265-273.

Hirshberg, M. J., Goldberg, S., Rosenkranz, M. A., \& Davidson, R. J. (2020). Prevalence of harm in Mindfulness-Based Stress Reduction. https://doi.org/10.31234/osf.io/d26m4

Hoaglin, D. C., Iglewicz, B., \& Tukey, J. W. (1986). Performance of Some Resistant Rules for Outlier Labeling. Journal of the American Statistical Association, 81(396), 991-999.

Hölzel, B. K., Lazar, S. W., Gard, T., Schuman-Olivier, Z., Vago, D. R., \& Ott, U. (2011). How Does Mindfulness Meditation Work? Proposing Mechanisms of Action From a Conceptual and Neural Perspective. Perspectives on Psychological Science, 6(6), 537-559. https://doi.org/10.1177/1745691611419671

Humboldt, S., Monteiro, A., \& Leal, I. (2017). Validation of the PANAS: A Measure of Positive and Negative Affect for Use with Cross-National Older Adults. Review of European Studies, 9(2), 10. https://doi.org/10.5539/res.v9n2p10

Huppert, F. A., \& So, T. T. C. (2011). Flourishing Across Europe: Application of a New Conceptual Framework for Defining Well-Being. Social Indicators Research, 110(3), 837-861. https://doi.org/10.1007/s11205-011-9966-7

Hutz, C. S., Midgett, A., Pacico, J. C., Bastianello, M. R., \& Zanon, C. (2014). The Relationship of Hope, Optimism, Self-Esteem, Subjective Well-Being, and Personality in Brazilians and Americans. Psychology, 5, 514-522.

International Wellbeing Group. (2006). Personal Wellbeing Index Adult, Manual 4th Edition, Melbourne: Australian Centre on Quality of Life, Deakin University.

International Wellbeing Group (2013). Personal Wellbeing Index: 5th Edition. Melbourne: Australian Centre on Quality of Life, Deakin University. http://www.acqol.com.au/instruments\#measu res

Jones, P. (2018). Mindfulness-based heroism: creating enlightened heroes. Journal of Humanistic Psychology, 58(5), 501-524. https://doi.org/10.1177/0022167817711303

Jones, P. (2019). Mindfulness Training: Can It Create Superheroes? Frontiers in Psychology, 10. https://doi.org/10.3389/fpsyg.2019. 00613

Juszczak, E., Altman, D. G., Hopewell, S., \& Schulz, K. (2019). Reporting of Multi-Arm Parallel-Group Randomized Trials. JAMA, 321(16), 1610. https://doi.org/10.1001/jama.2019.3087

Kabat-Zinn, J. (1990). Full catastrophe living: Using the wisdom of your body and mind to face stress, pain and illness. Delacorte.

Kabat-Zinn, J. (2003). Mindfulness-Based Interventions in Context: Past, Present, and Future. Clinical Psychology: Science and Practice, 10(2), 144-156. https://doi.org/10.1093/clipsy/bpg016

Kabat-Zinn, J. (2011). Some reflections on the origins of MBSR, skilful means, and the trouble with maps. Contemporary Buddhism, 12, 281-306.

Karanicolas, P. J., Farrokhyar, F., \& Bhandari, M. (2010). Practical tips for surgical research: blinding: who, what, when, why, how? Canadian journal of surgery, 53(5), 345-348.

Karimi, M., \& Brazier, J. (2016). Health, Health-Related Quality of Life, and Quality of Life: What is the Difference? PharmacoEconomics, 34(7), 645-649. https://doi.org/10.1007/ s40273-016-0389-9

Keng, S. L., Smoski, M. J., \& Robins, C. J. (2011). Effects of mindfulness on psychological health: A review of empirical studies.
Clinical Psychology Review, 31, 1041-1056. https://doi.org/10. 1016/j.cpr.2011.04.006

Kirby, J. N., Tellegen, C. L., \& Steindl, S. R. (2017). A meta-analysis of compassion-based interventions: current state of knowledge and future directions. Behavior Therapy, 48(6), 778-792. https:// doi.org/10.1016/j.beth.2017.06.003

Krampen, G. (1999). Evaluation of the effectiveness of autogenic training in gerontopsychology. European Psychologist, 1(4), 243-254.

Kreplin, U., Farias, M., \& Brazi, I. A. (2018). The limited prosocial effects of meditation: A systematic review and metaanalysis. Scientific Reports, 8, 2403. https://doi.org/10.1038/ s41598-018-20299-z

Kudesia, R. S., \& Nyima, T. (2014). Mindfulness contextualized: An integration of Buddhist and neuropsychological approaches to cognition. Mindfulness, 6, 910-925.

Lac, A., \& Donaldson, C. D. (2018). Validation and psychometric properties of the Alcohol Positive and Negative Affect Schedule: Are drinking emotions distinct from general emotions? Psychology of Addictive Behaviors, 32(1), 40-51. https://doi.org/10.1037/ adb0000343

Lachman, M. E., Teshale, S., \& Agrigoroaei, S. (2015). Midlife as a pivotal period in the life course: Balancing growth and decline at the crossroads of youth and old age. International Journal of Behavioral Development, 39, 20-31. https://doi.org/10.1177/ 0165025414533223

Lance, C. E., Butts, M. M., \& Michels, L. C. (2006). The Sources of Four Commonly Reported Cutoff Criteria: What Did They Really Say? Organizational Research Methods, 9(2), 202-220.

Land, K. C., Michalos, A. C., \& Sirgy, M. J. (2011). Prologue: The Development and Evolution of Research on Social Indicators and Quality of Life (QOL). Handbook of Social Indicators and Quality of Life Research, 1-22. https://doi.org/10.1007/ 978-94-007-2421-1_1

Lapierre, S., Dubé, M., Bouffard, L., \& Alain, M. (2007). Addressing Suicidal Ideations Through the Realization of Meaningful Personal Goals. Crisis, 28(1), 16-25. https://doi.org/10.1027/ 0227-5910.28.1.16

Larson, R. (1989). Is Feeling "in Control" Related to Happiness in Daily Life? Psychological Reports, 64(3), 775-784. https://doi. org/10.2466/pr0.1989.64.3.775

Lau, A. L. D., Cummins, R. A., \& Mcpherson, W. (2005). An Investigation into the Cross-Cultural Equivalence of the Personal Wellbeing Index. Social Indicators Research, 72(3), 403-430. https:// doi.org/10.1007/s11205-004-0561-z

Lee, V. S. (2001). Learning that Lasts: Integrating Learning, Development, and Performance in College and Beyond (review). The Journal of General Education, 50(3), 230-233. https://doi.org/ 10.1353/jge.2001.0019

Levinson, D. B., Stoll, E. L., Kindy, S. D., Merry, H. L., \& Davidson, R. J. (2014). A mind you can count on: validating breath counting as a behavioral measure of mindfulness. Frontiers in Psychology, 5. https://doi.org/10.3389/fpsyg.2014.01202

Lindahl, J. R., \& Britton, W. B. (2019). I Have This Feeling of Not Really Being Here. Journal of Consciousness Studies, 26(7-8), 157-183.

Lloyd, K. M., \& Auld, C. J. (2002). The role of leisure in determining quality of life: Issues of content and measurement. Social Indicators Research, 57, 43-71.

Locke, E. A., \& Latham, G. P. (2013). New developments in goal setting and task performance. Routledge. 
Locke, E. A., \& Schattke, K. (2018). Intrinsic and extrinsic motivation: Time for expansion and clarification. Motivation Science. https:// doi.org/10.1037/mot0000116

López Ulloa, B. F., Møller, V., \& Sousa-Poza, A. (2013). How Does Subjective Well-Being Evolve with Age? A Literature Review. Journal of Population Ageing, 6(3), 227-246. https://doi.org/10. 1007/s12062-013-9085-0

Luhmann, M., Hofmann, W., Eid, M., \& Lucas, R. E. (2012). Subjective well-being and adaptation to life events: A meta-analysis. Journal of Personality and Social Psychology, 102(3), 592-615. https://doi.org/10.1037/a0025948

Lutz, A., Brefczynski-Lewis, J., Johnstone, T., \& Davidson, R. J. (2008). Regulation of the Neural Circuitry of Emotion by Compassion Meditation: Effects of Meditative Expertise. PLOS ONE, 3(3), e1897. https://doi.org/10.1371/journal.pone.0001897

Lyubomirsky, S. (2013). The myths of happiness: What should make you happy, but doesn't, what shouldn't make you happy, but does. Penguin.

Malinowski, P. (2013). Neural mechanisms of attentional control in mindfulness meditation. Frontiers in Neuroscience, 7, 1-11.

Malkoç, A. (2011). Quality of life and subjective well-being in undergraduate students. Procedia - Social and Behavioral Sciences, 15, 2843-2847. https://doi.org/10.1016/j.sbspro.2011.04.200

Maxwell, A., Özmen, M., Iezzi, A., \& Richardson, J. (2016). Deriving population norms for the AQoL-6D and AQoL-8D multiattribute utility instruments from web-based data. Quality of Life Research, 25(12), 3209-3219. https://doi.org/10.1007/ s11136-016-1337-z

Moher, D., Hopewell, S., Schulz, K. F., Montori, V., Gotzsche, P. C., Devereaux, P. J., et al. (2010). CONSORT 2010 Explanation and Elaboration: updated guidelines for reporting parallel group randomised trials. BMJ, 340(mar23 1), c869-c869. https://doi.org/ 10.1136/bmj.c869

Monnot, M. J., \& Beehr, T. A. (2014). Subjective well-being at work: Disentangling source effects of stress and support on enthusiasm, contentment, and meaningfulness. Journal of Vocational Behavior, 85, 204-218.

Natarajan, A. R. (2000). Ramana Maharshi Answers 100 Questions. Ramana Maharshi Centre for Learning.

Neff, K. D. (2011). Self-Compassion, Self-Esteem, and Well-Being. Social and Personality Psychology Compass, 5(1), 1-12. https:// doi.org/10.1111/j.1751-9004.2010.00330.x

Newington, L., \& Metcalfe, A. (2014). Factors influencing recruitment to research: qualitative study of the experiences and perceptions of research teams. BMC Medical Research Methodology, 14(1). https://doi.org/10.1186/1471-2288-14-10

Newman, D. B., Tay, L., \& Diener, E. (2013). Leisure and Subjective Well-Being: A Model of Psychological Mechanisms as Mediating Factors. Journal of Happiness Studies, 15(3), 555-578. https://doi.org/10.1007/s10902-013-9435-x

Nickel, L. B., Roberts, B. W., \& Chernyshenko, O. S. (2019). No evidence of a curvilinear relation between conscientiousness and relationship, work, and health outcomes. Journal of Personality and Social Psychology, 116(2), 296-312. https://doi.org/10.1037/ pspp0000176

Nunnally, J. C., \& Bernstein, I. H. (1994). Psychometric theory (3rd ed.). New York, NY: McGraw-Hill, Inc

Ortner, C. N. M., \& Zelazo, P. D. (2014). Responsiveness to a mindfulness manipulation predicts affect regarding an anger-provoking situation. Canadian Journal of Behavioural Science / Revue Canadienne Des Sciences Du Comportement, 46(2), 117-124. https://doi.org/10.1037/a0029664
Parfyonova, N. M., Meyer, J. P., Espinoza, J. A., Anderson, B. K., Cameron, K. A., Daljeet, K. N., \& Vaters, C. (2019). Managerial support for employees' psychological needs: A multidimensional approach. Canadian Journal of Behavioural Science, 51(2), 122134. https://doi.org/10.1037/cbs0000126

Pavot, W., \& Diener, E. (1993). Review of the Satisfaction With Life Scale. Psychological Assessment, 5(2), 164-172. https://doi.org/ 10.1037/1040-3590.5.2.164

Pavot, W., \& Diener, E. (2009). Review of the Satisfaction With Life Scale. Social Indicators Research Series, 101-117. https://doi. org/10.1007/978-90-481-2354-4_5

Peasgood, T., Carlton, J., \& Brazier, J. (2019). A Qualitative Study of the Views of Health and Social Care Decision-makers on the Role of Wellbeing in Resource Allocation Decisions in the UK. Economies, 7(1), 14. https://doi.org/10.3390/economies7010014

Peterson, C., Park, N., \& Seligman, M. E. P. (2005). Orientations to happiness and life satisfaction: the full life versus the empty life. Journal of Happiness Studies, 6(1), 25-41. https://doi.org/10. 1007/s10902-004-1278-z

Plemmons, S. A., \& Weiss, H. M. (2013). Goals and affect. In E. A. Locke \& G. P. Latham (Eds.), New developments in goal setting and task performance (pp. 117-132). Psychology Press.

Proulx, C. M., Helms, H. M., \& Buehler, C. (2007). Marital quality and personal well-being: A meta-analysis. Journal of Marriage and Family, 69, 576-593.

Raffone, A., \& Srinivasan, N. (2009). The exploration of meditation in the neuroscience of attention and consciousness. Cognitive Processing, 11, 1-7.

Richardson J., Iezzi A., Khan M.A., \& Maxwell A. (2013). Validity and reliability of the Assessment of Quality of Life (AQoL-8D) multi attribute utility instrument. The Patient: Patient-Centered Outcomes Research. https://doi.org/10.1007/s40271-013-0036-X

Robins, R. W., Tracy, J. L., Trzesniewski, K., Potter, J., \& Gosling, S. D. (2001). Personality Correlates of Self-Esteem. Journal of Research in Personality, 35(4), 463-482. https://doi.org/10.1006/ jrpe.2001.2324

Rodríguez, A., Látková, P., \& Sun, Y. Y. (2007). The relationship between leisure and life satisfaction: application of activity and need theory. Social Indicators Research, 86(1), 163-175. https:// doi.org/10.1007/s11205-007-9101-y

Ryff, C. D. (1989). Happiness is everything, or is it? Explorations on the meaning of psychological wellbeing. Journal of Personality and Social Psychology, 57(6), 1069.

Salvador-Carulla, L., Lucas, R., Ayuso-Mateos, J. L., \& Miret, M. (2014). Use of the terms "Wellbeing" and "Quality of Life" in health sciences: a conceptual framework. The European Journal of Psychiatry, 28(1), 50-65. https://doi.org/10.4321/s0213-61632 014000100005

Sedlmeier, P., Eberth, J., Schwarz, M., Zimmermann, D., Haarig, F., Jaeger, S., et al. (2012). The psychological effects of meditation: a meta-analysis. Psychological. Bulletin., 138, 1139-1171. https://doi.org/10.1037/a0028168

Segal, Z., Williams, J. M. G., \& Teasdale, J. (2002). Mindfulness-based cognitive therapy for depression: A new approach to preventing relapse. Guilford Press.

Seijts, G. H., Latham, G. P., \& Woodwark, M. (2013). Learning goals: A qualitative and quantitative review. In E. A. Locke \& G. P. Latham (Eds.), New developments in goal setting and task performance (pp. 195-212). Routledge/Taylor \& Francis Group.

Sinclair, S. J., Siefert, C. J., Slavin-Mulford, J. M., Stein, M. B., Renna, M., \& Blais, M. A. (2011). Psychometric Evaluation and Normative Data for the Depression, Anxiety, and Stress Scales-21 (DASS-21) in a Nonclinical Sample of U.S. Adults. Evaluation \& 
the Health Professions, 35(3), 259-279. https://doi.org/10.1177/ 0163278711424282

Sarenmalm, E. K., Mårtensson, L. B., Holmberg, S. B., Andersson, B. A., Odén, A., \& Bergh, I. (2013). Mindfulness based stress reduction study design of a longitudinal randomized controlled complementary intervention in women with breast cancer. $B M C$ Complementary and Alternative Medicine, 13(1). https://doi.org/ 10.1186/1472-6882-13-248

Schoenberg, P., \& Vago, D. R. (2018). Mapping Meditative States and Stages with Electrophysiology: Concepts. Classifications, and Methods. https://doi.org/10.31231/osf.io/3r46u

Shonin, E., Van Gordon, W., \& Griffiths, M. D. (2014). The emerging role of Buddhism in clinical psychology: toward effective integration. Psychology of Religion and Spirituality, 6, 123-137.

Schulz, K. F. (2010). CONSORT 2010 Statement: Updated Guidelines for Reporting Parallel Group Randomized Trials. Annals of Internal Medicine, 152(11), 726. https://doi.org/10.7326/0003-4819152-11-201006010-00232

Sergeant, S., \& Mongrain, M. (2015). Distressed users report a better response to online positive psychology interventions than nondistressed users. Canadian Psychology/Psychologie Canadienne, 56(3), 322-331. https://doi.org/10.1037/cap0000034

Shapiro, S. L., Brown, K. W., \& Biegel, G. M. (2007). Teaching selfcare to caregivers: Effects of mindfulness-based stress reduction on the mental health of therapists in training. Training and Education in Professional Psychology, 1(2), 105-115. https://doi. org/10.1037/1931-3918.1.2.105

Sheldon, K. M., Ryan, R. M., Deci, E. L., \& Kasser, T. (2004). The independent effects of goal contents and motives on well-being: It's both what you pursue and why you pursue it. Personality and Social Psychology Bulletin, 30, 475-486.

Shimazu, A., Schaufeli, W. B., Kamiyama, K., \& Kawakami, N. (2015). Workaholism vs. work engagement: the two different predictors of future well-being and performance. International Journal of Behavioral Medicine, 22(1), 18-23.

Shonin, E., Van Gordon, W., Compare, A., Zangeneh, M., \& Griffiths, M. D. (2015). Buddhist derived loving-kindness and compassion meditation for the treatment of psychopathology: A systematic review. Mindfulness, 6(5), 1161-1180. https://doi.org/10.1007/ s12671-014-0368-1

Sin, N. L., \& Lyubomirsky, S. (2009). Enhancing well-being and alleviating depressive symptoms with positive psychology interventions: a practice-friendly meta-analysis. Journal of Clinical Psychology, 65(5), 467-487. https://doi.org/10.1002/jclp.20593

Sitbon, A., Shankland, R., \& Krumm, C. M. (2019). Interventions efficaces en psychologie positive: Une revue systématique Alternate title: Effective interventions in positive psychology: A systematic review. Canadian Psychology/Psychologie Canadienne, 60(1), 35-54. https://doi.org/10.1037/cap0000163

Skevington, S. M., \& Böhnke, J. R. (2018). How is subjective wellbeing related to quality of life? Do we need two concepts and both measures? Social Science \& Medicine, 206, 22-30. https:// doi.org/10.1016/j.socscimed.2018.04.005

Smith, W. P., Compton, W. C., \& West, W. B. (1995). Meditation as an adjunct to a happiness enhancement program. Journal of Clinical Psychology, 51(2), 269-273.

Sonnentag, S., \& Niessen, C. (2008). Staying vigorous until work is over: The role of trait vigour, day-specific work experiences and recovery. Journal of Occupational and Organizational Psychology, 81(3), 435-458. https://doi.org/10.1348/096317908x310256

Sőrés, A., \& Pető, K. (2015). Measuring of Subjective Quality of Life. Procedia Economics and Finance, 32, 809-816. https://doi.org/ $10.1016 / \mathrm{s} 2212-5671(15) 01466-5$
Steptoe, A., Deaton, A., \& Stone, A. A. (2015). Subjective wellbeing, health, and ageing. The Lancet, 385(9968), 640-648. https://doi. org/10.1016/s0140-6736(13)61489-0

Strickland, B. R. (2016). Internal Versus External Locus of Control. Perceived Control, 23-44. https://doi.org/10.1093/acprof:oso/ 9780190257040.003 .0002

Suresh, K. (2011). An overview of randomization techniques: An unbiased assessment of outcome in clinical research. Journal of Human Reproductive Sciences, 4(1), 8. https://doi.org/10.4103/ 0974-1208.82352

Tacon, A. M., Caldera, Y. M., \& Ronaghan, C. (2004). MindfulnessBased Stress Reduction in Women With Breast Cancer. Families, Systems, \& Health, 22(2), 193-203.

Tan, K. \& Tay, L. (2017). Relationships and well-being. In R. BiswasDiener \& E. Diener (Eds), Noba textbook series: Psychology. Champaign, IL: DEF publishers.

Tay, L., Kuykendall, L., \& Diener, E. (2014). Satisfaction and Happiness - The Bright Side of Quality of Life. Global Handbook of Quality of Life, 839-853. https://doi.org/10.1007/978-94-0179178-6_39

Taylor, S. E. (2010). Social support: A review. In H. S. Friedman (Ed.), Oxford Handbook of Health Psychology. Oxford University Press.

Teshale, S. M., \& Lachman, M. E. (2016). Managing Daily Happiness: The Relationship Between Selection, Optimization, and Compensation Strategies and Well-Being in Adulthood. Psychology and Aging, 31(7), 687-692. https://doi.org/10.1037/pag0000132

The World Health Organisation (WHO) (2015). World Happiness Report 2015. Geneva, 640 Switzerland, World Health Organisation http://worldhappiness.report/ed/2015

Thomas, J. (2005). Yogic lifestyle and subjective wellbeing. http://www. yogamag.net/archives/2008/bfeb08/life.shtml

Thomas, J., Raynor, M., \& Bahussain, E. (2016). Stress reactivity, depressive symptoms, and mindfulness: A Gulf Arab perspective. International Perspectives in Psychology: Research, Practice, Consultation, 5(3), 156-166. https://doi.org/10.1037/ipp0000055

Threadgill, A. H., \& Gable, P. A. (2018). The sweetness of successful goal pursuit: Approach-motivated pregoal states enhance the reward positivity during goal pursuit. International Journal of Psychophysiology, 132, 277-286. https://doi.org/10.1016/j.ijpsy cho.2017.12.010

Tinsley, H. E., \& Eldredge, B. D. (1995). Psychological benefits of leisure participation: A taxonomy of leisure activities based on their need-gratifying properties. Journal of Counseling Psychology, 42, 123-132.

Vago, D. R., \& Nakamura, Y. (2011). Selective attentional bias towards pain-related threat in fibromyalgia: preliminary evidence for effects of mindfulness meditation training. Cognitive Therapy Research, 35, 581-594.

Vago, D. R., \& Silbersweig, D. A. (2012). Self-awareness, self-regulation, and self-transcendence (S-ART): a framework for understanding the neurobiological mechanisms of mindfulness. Frontiers in Human Neuroscience, 6, 296.

Van Dam, N. T., Earleywine, M., \& Borders, A. (2010). Measuring mindfulness? An Item Response Theory analysis of the Mindful Attention Awareness Scale. Personality and Individual Differences, 49(7), 805-810. https://doi.org/10.1016/j.paid.2010.07. 020

Van Gordon, W., Shonin, E., \& Griffiths, M. D. (2015). Towards a second-generation of mindfulness-based interventions. Australia and New Zealand Journal of Psychiatry, 49, 591-593. 
Van Gordon, W., \& Shonin, E. (2020). Second-Generation Mindfulness-Based Interventions: Toward More Authentic Mindfulness Practice and Teaching. Mindfulness, 11, 1-4.

Van Katwyk, P. T., Fox, S., Spector, P. E., \& Kelloway, E. K. (2000). Using the Job-Related Affective Well-being Scale (JAWS) to investigate affective responses to work stressors. Journal of Occupational Health Psychology, 52, 219-230.

van Leeuwen, S., Muller, N. G., \& Melloni, L. (2009). Age effects on attentional blink performance in meditation. Consciousness and Cognition, 18, 593-599. https://doi.org/10.1016/j.concog. 2009.05.001

Van Merriënboer, J. J. G., \& Kirschner, P. A. (2017). Ten Steps. Ten Steps to Complex Learning, 39-51. https://doi.org/10.4324/ 9781315113210-3

Watson, D., Clark, L. A., \& Tellegen, A. (1988). Development and validation of brief measures of positive and negative affect: The PANAS scales. Journal of Personality and Social Psychology, 54(6), 1063-1070.
Whisman, M. A., \& Judd, C. M. (2016). A cross-national analysis of measurement invariance of the Satisfaction With Life Scale. Psychological Assessment, 28(2), 239-244. https://doi.org/10. 1037/pas0000181

Wlodkowski, R. J., \& Westover, T. (1999). Accelerated Courses as a Learning Format for Adults. The Canadian Journal for the Study of Adult Education, 131, 1-20.

Zettle, R., \& Gird, S. (2016). Acceptance and Mindfulness-Based Interventions. Oxford Handbooks Online. https://doi.org/10.1093/ oxfordhb/9780199973965.013.37

Publisher's note Springer Nature remains neutral with regard to jurisdictional claims in published maps and institutional affiliations. 